\title{
Clinton e a reinvenção do governo federal: o National Performance Review ${ }^{1}$
}

\section{Introdução}

Este artigo analisa a natureza e a formação da agenda de reformas (agenda setting), a sequiência de implementação, as principais inovações, a dinâmica político-institucional e alguns dos resultados alcançados pelo National Performance Review, programa de reforma administrativa na administração do presidente Bill Clinton implementado em 1993. ${ }^{2}$

A discussão sobre a natureza e a formação da agenda do programa tem por objetivos centrais entender os princípios e os objetivos programáticos deste programa de reforma do setor público, ressaltando as bases conceituais em que se assenta este esforço de reforma, os pontos de inovação sobre formas de pensar e agir sobre a administração pública americana, sobre o papel e missão do governo federal na economia e na sociedade americana, bem como as principais especificidades desta agenda em relação a outras experiências de reformas nos Estados Unidos e no plano internacional. A atenção central dos esforços desta análise permite entender o novo paradigma empreendedorialista proposto pelo NPR para o funcionamento da burocracia no governo federal americano.

A avaliação dos resultados do programa tem por objetivo dotar o trabalho de uma base empírica capaz de permitir compreender como alguns dos resultados pretendidos pelo programa foram obtidos nas principais agências e departamentos do governo americano. A análise dos resultados obtidos pelo NPR utiliza as seguintes variáveis: redução do número de funcionários, controle dos political appointees (cargos de confiança); efetividade na redução do gasto público e efetividade na implementação das recomendações propostas pelo programa. Esta breve aferição de alguns resultados pontuais do programa não permite avaliações de natureza 
normativa sobre o sucesso ou insucesso do programa, ${ }^{3}$ e se constitue como um elemento suporte para os pontos principais apresentados ao longo do texto em torno dos objetivos programáticos do NPR.

O artigo está organizado da seguinte forma: na primeira parte, os princípios, objetivos e a natureza da agenda do programa são apresentados. Em seguida, o foco se volta para uma compreensão da formação da agenda e da seqüência de implementação das reformas. Na terceira parte, privilegia-se a análise da dinâmica político-institucional em torno do programa de reformas, com destaque para as tensões entre o Legislativo e Executivo em torno das reformas, e o seu impacto sobre a mudanca de preferências na agenda do programa. A última parte apresenta um painel empírico sobre alguns dos resultados obtidos pelo programa em agências e departamentos do governo em áreas de interesse à análise. Na parte final também são apresentados comentários finais e alguns pontos de interesse para a condução das reformas administrativas em curso no Brasil.

\section{Contextualizando a necessidade de reformas no setor público nos Estados Unidos}

A iniciativa de reorganização do Executivo federal constitui tema recorrente na agenda de políticas públicas nos Estados Unidos. Tanto para republicanos como para democratas de diversas orientações e visões sobre o papel do governo federal, a preocupação com a melhoria qualitativa dos padrões de administração federal foi materializada em programas específicos de reformas, com diferentes objetivos e missões ao longo do tempo. A literatura temática assinala 11 (onze) macroprogramas federais destinados a alterar padrões de administração federal desde o início do século. ${ }^{4}$ No período anterior ao New Deal, os três governos republicanos (1905-1924) formulam e implementam três programas: a Keep Commission, o President's Commission on Economy and Efficiency, e a Joint Commission on Reorganization, os quais tinham como objetivo central realizar alterações nos sistemas de orçamento das agências, gestão de pessoal, controle da informação, e ainda estruturar as funções do governo federal. A partir do New Deal, quando o governo federal americano inaugura a era democrática, tais questões permanecem reavivadas num momento de expansão dos governos e dos gastos públicos. Com o presidente Franklin Roosevelt (1901-1909) o governo federal inaugura a agenda de reformas no President's Commission on Administrative Management (1936-1937). Tal esforço programático se transforma na famosa Primeira Comissão Hoover (1947-1949) implementada durante o governo de Henry Truman (1945-1953), onde o governo passa a se preocupar com a questão orçamentária de forma mais significativa. A segunda Comissão Hoover 
(1953-1955) que viria a acontecer nas duas gestões do republicano Dwight Eisenhower (1953-1961) focaliza-se em alterações, na redistribuição de funções administrativas no Executivo. Nos anos 60, a reorganização federal na agenda republicana reaparece com Nixon (1969-1974), com a implementação da Ash Commission, um programa focalizado na reestruturação do Executivo federal num contexto de completa transformação dos padrões de governança nos Estados Unidos. No governo de Carter (1977-1981), as questões de reorganização interna do governo são condensadas no Carter Reorganization Effort (1977-1979), um tímido esforço de reformas, mas que, no entanto, tinha por objetivo central reorganizar os processos internos nas estruturas da administração pública. Contudo, é nos anos 80, com o governo Reagan (1981-1989), que a preocupação com o controle dos custos do governo e uma maior austeridade fiscal do governo se torna objetivo programático da agenda de reformas. Pela primeira vez, as reformas administrativas se associariam de modo mais intenso com a questão da restrição de recursos, onde os imperativos de eficiência e qualidade na gestão pública se tornam os princípios balizadores de tais políticas públicas.

Na grande parte dos estudos realizados no escopo destes programas, o diagnóstico recorrente, sob diversas orientações, é o de que a administração federal apresenta problemas derivados de excessiva regulação interna, centralização da gestão e coordenação das decisões no Legislativo e na Presidência, superposição de competências e funções, alta hierarquização, resistência à mudança e inovação nos procedimentos e mecanismos internos de regulação da burocracia, descompasso entre demandas por recursos e objetivos das agências, e ainda deficiências nos sistemas internos de controle e difusão da informação para tomada de decisões. Estes elementos têm contribuído para uma burocracia que funciona com reduzida accountability, associada a excessivos gastos públicos, combinação que tem orientado de modo decisivo os programas de reformas e reorganizações no sistema de administração do Executivo federal americano.

Tais problemas se tornaram visivelmente mais agudos com a entrada em cena da crise econômica e financeira desencadeada no anos 80 , quando os padrões democráticos de expansão do governo eficiente tornaram-se absolutamente incompatíveis com a governança. Os governos têm progressivamente se preocupado com a questão do controle do gasto público e procurado implementar mecanismos voltados para reduzir os programas governamentais, desregular e privatizar funções públicas, e sobretudo, alterar o papel do governo federal numa economia progressivamente competitiva e global, e numa sociedade democrática, com intensa demanda por melhores serviços públicos. 
Diante de tais requisitos, os padrões e os modos de administração pública tradicionais têm sido profundamente questionados em torno de suas capacidades de se ajustar aos novos imperativos por melhor governo em ambientes marcados por controle orçamentário e fiscal. $\mathrm{O}$ argumento de que os padrões tradicionais de gestão pública devem ser revistos tem adquirido considerável visibilidade na formulação das agendas de reformas administrativas, tornando-se decisivo a partir de meados dos anos 80 , quando o Presidente Reagan, com sua orientação neoliberal centrada nos princípios do supply-side economics, lança de modo agressivo um programa de combate à burocracia e um programa de privatizações, fazendo com que o governo passe a ser a raiz dos diversos problemas econômicos e financeiros do país.

É exatamente neste período que os programas federais de reorganização federal passam a ser profundamente atrelados à questão fiscal, a qual tinha sido questão secundária no momento de expansão do governo. Os governos nos anos 80 - Reagan (1981-1989), e Bush (19891993) - implementam esforços programáticos no sentido de alterar o padrão de intervenção do governo federal na economia e na sociedade americana, e ainda o padrão de envolvimento dos mercados nas políticas públicas. A crítica ao padrão centralizado e hierárquico produzido pelo modo de pensar e organizar a administração pública federal, no entanto, passa despercebida por tais programas de reformas. $\mathrm{O}$ ataque à burocracia e o controle austero das finanças públicas, descentralização, devolução de autoridade para os governos locais, desregulamentação e privatização assumem o comando da agenda.

Tais programas promoveram uma significativa inflexão no padrão de gastos públicos nos EUA. Como apresentado no Gráfico 1, o ano fiscal de 1985 representa um ponto de inflexão do padrão histórico de gastos do governo, onde a partir do qual o controle do gasto público assume decisiva e marcante presença. As reformas administrativas passam, portanto, de instrumentos apenas de melhoria das organizações em si, dos seus processos internos, para uma conexão mais profunda com os propósitos mais amplos de controlar a expansão do governo. Em diferentes agendas e ambientes políticos, as reformas administrativas que emergem a partir dos anos 80, diferentemente daquelas formuladas e implementadas nos períodos anteriores, podem ser entendidas como políticas públicas que expressam as preferências políticas em atingir o objetivo de controle dos gastos e equilíbrio orçamentário federal. 


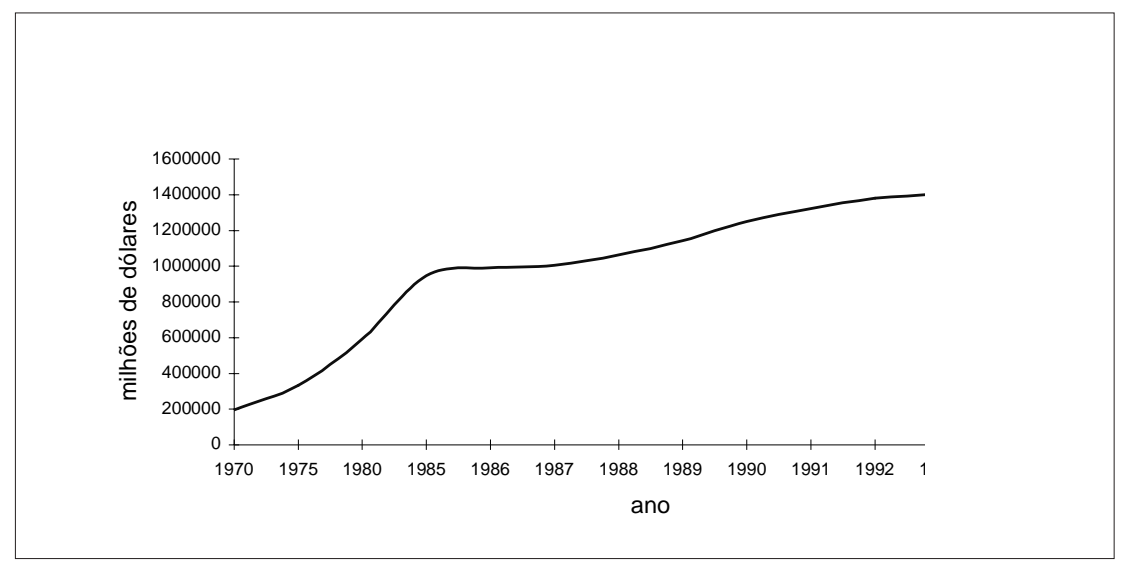

Tal preferência política balizou a agenda de políticas públicas do presidente democrata Bill Clinton (1993-1996) no seu programa de reformas do setor público. Para o governo Clinton, os imperativos da competitividade econômica na arena internacional, o avanço da era da informação e as demandas internas por melhores políticas públicas fizeram das reformas uma das prioridades da agenda, juntamente com a questão do NAFTA - North American Free Trade Agreement; e o crônico problema de melhoria dos sistemas de seguridade social, atenção à saúde, educação e proteção ao meio ambiente. Para o governo Clinton, independente de posição partidária dos democratas, o governo americano precisaria enfrentar reformas mais profundas, as quais deveriam ir além das tentativas de controle dos gastos, mas, que pudessem dar respostas concretas às demandas por melhor e mais eficientes serviços públicos. O desafio central para a agenda Clinton seria, portanto, o de encontrar mecanismos pelos quais fosse possível combinar controle dos gastos públicos (balance the budget) ao melhor funcionamento da administração pública federal. Tais objetivos se revelam logo num dos primeiros pronunciamentos do presidente Clinton para o Congresso de maioria democrática em 1993, quando este afirma que "a era do big government acabou", e que um novo padrão de organização e funcionamento do governo que funcionasse melhor e custasse menos, fosse introduzido de forma permanente, revisando profundamente as estruturas e os modos sob os quais a administração pública federal vinha funcionando desde o início do século. Tal ambiciosa missão seria materializada na sua agenda de reformas, no programa National Performance Review formulado em março de 1993, a qual introduziu a necessidade de reinvenção ${ }^{5}$ do governo federal no sentido de lidar de forma efetiva com os crônicos problemas e patologias da administração 
pública federal. Como afirma o próprio Clinton, o objetivo central do programa de reformas é:

"o de dar ao povo americano um governo mais efetivo, eficiente, e responsivo: um governo que custa menos e funciona melhor. ${ }^{6}$ O NPR começou em 3 de março de 1993, quando solicitei ao vicepresidente, Al Gore, para conduzir um diagnóstico de seis meses sobre como o governo federal funciona. $\mathrm{O}$ vice-presidente organizou uma equipe de experientes funcionários federais nas diversas áreas do governo para examinar tanto as agências como os sistemas inter-agências, tais como os sistemas de orçamentação, gestão financeira, regulamentação e gestão de pessoal".?

O programa de reinvenção introduzido pelo governo Clinton pretendeu superar os problemas burocráticos no sistema de governança americano ao introduzir mudanças significativas nas relações formais de poder e autoridade no interior das agências e departamentos do governo, entre os poderes Executivo e Legislativo, e ainda nas relações inter-agências, elementos considerados fundamentais para uma qualitativa transformação do papel do governo na economia e na sociedade. A análise dos princípios, da natureza da agenda e dos objetivos programáticos do NPR é realizada na parte seguinte.

\section{A agenda de reformas e o NPR}

\subsection{Natureza da agenda, objetivos e princípios gerais do programa de reformas}

A agenda de reformas do presidente Clinton ficaria demarcada com maior precisão a partir do lançamento do relatório Creating a government that works better and costs less, o qual contém o conjunto de recomendações e iniciativas a serem perseguidas no programa National Performance Review (NPR). O ponto de partida para a materialização de tal agenda foi baseado num detalhado diagnóstico realizado em seis meses por uma equipe, contando com os melhores especialistas (mais de 250 funcionários) nos diversos setores da burocracia federal sobre o funcionamento das diversas agências e departamentos do governo, seus problemas principais e oportunidades para as reformas.

A equipe de alto comando responsável pela preparação do primeiro relatório do NPR envolveu David Osborne, um dos autores e principais difusores da idéia de reinvenção do governo, como orientador especial do programa; Elaine Lamarck, a qual se tornaria a principal consultora do vice-presidente Al Gore; Robert Stone, que viria a ser o diretor do projeto 
NPR; Billy Hamilton, com experiência no funcionamento de diversas agências do governo; John Kamensky, especialista em sistemas de orçamento e sistemas de gestão de pessoal; Bob Kinsley, especialista em questões de natureza fiscal; e Carolyn Lukensmeyer, especialista em questões da dinâmica interna e das comunicações. ${ }^{8}$

O estudo realizado pelos formuladores do NPR expressa sintonia com o diagnóstico de especialistas de diversas formações teóricas e ideológicas (Fiorina 1981; Osborne \& Gaebler 1992; Di Iulio, Garvey \& KetTl 1993; Di Iulıo 1994) de que grande parcela dos problemas da administração pública federal estariam associados aos sistemas de estruturas de incentivos sob os quais estas funcionam e se organizam. Com efeito, a forte crítica dos especialistas do NPR recaiu sobre a excessiva interferência do Legislativo sobre a burocracia federal. Nesta perspectiva, os incentivos internos de funcionamento da burocracia federal eram incompatíveis com a autonomia gerencial das organizações públicas, as quais eram fortemente constrangidas no sentido de orientar suas ações por padrões de qualidade e eficiência na prestação de serviços para o consumidor final. Esta crítica ao excesso de regulação do Legislativo viria a ser o ponto nevrálgico de todas as reformas propostas pelo NPR. Baseado neste diagnóstico, o programa de reinvenção do governo foi concebido e fundamentalmente implementado no sentido de alterar os mecanismos internos (incentivos) pelos quais a burocracia federal opera e se organiza, fazendo com que esta se volte gradualmente para prestar melhores serviços para os usuários e clientes dos programas governamentais, a partir de uma gradual "desregulamentação" dos mecanismos que inibem o melhor funcionamento das organizações do governo. Este objetivo deveria ser alcançado a partir de uma revisão das relações de poder e autoridade entre o Legislativo e Executivo na questão da administração pública. Ao assumir tal premissa como fundamental às reformas, a reinvenção traria à tona uma necessidade de rever, mais amplamente, as bases de organização e funcionamento da burocracia.

Neste sentido, o NPR propõe um novo paradigma para orientar a burocracia, e mais amplamente a organização do governo. Este tema tinha estado ausente nas experiências anteriores de reformas, as quais deixaram relativamente intacto o modo de pensar e tratar os problemas burocráticos. O NPR introduz a noção de que a burocracia é, na realidade, um conjunto extremamente heterogêneo e fragmentado de agências, que devem ser melhor entendidas a partir de abordagens que possibilitem compreender estas especificidades, sobretudo no que se refere às necessidades específicas de reformas em cada setor e organização do governo federal. Esta concepção fragmentada de entender o funcionamento e os problemas burocráticos, como comentaremos adiante com maior detalhe, faria com que o NPR fosse dimensionado a partir de 
cada agência e departamento, porém, sob coordenação de princípios gerais formulados pelo governo federal. As visões homogeneizadoras praticadas no passado por outras experiências de reformas do governo deveriam ser evitadas no processo de reinvenção.

O estilo fragmentado do NPR se deve ainda ao fato de que cada organização do governo, dado a natureza pluralista da política americana, apresenta uma "política" própria à qual tem significativa conseqüência no grau em que cada organização se ajusta ao processo de reformas proposto. A experiência histórica das reformas nos EUA mostrou o relativo fracasso das visões mais "homogêneas", as quais privilegiaram iniciativas mais generalizadas para os problemas burocráticos num ambiente de alta diversidade. A abordagem fragmentada e concebida no bottom-top poderia ser mais efetiva em lidar com as resistências políticas em cada micro ambiente organizacional em que as reformas fossem implementadas.

Segundo os relatórios do programa, a preferência dos formuladores do NPR pela fragmentação das reformas foi claramente expressa, uma vez que aproximadamente $2 / 3$ das recomendações originalmente propostas tiveram um caráter individualizado por agências e departamentos, sendo o terço restante comum a todas as agências ou voltadas para organizações do governo que tratam com relações inter-agências. No que se refere à natureza das recomendações propostas, estas fundamentalmente se orientaram no sentido de que agências e departamentos passassem a alterar seus procedimentos e princípios de organização gerenciais, suas estruturas de incentivos internos, missões e objetivos organizacionais, prioridades alocativas, graus de autonomia e descentralização, sistemas de gestão e contratação de pessoal, no sentido de garantir eficiência e accountability na oferta de serviços públicos.

Um dos pontos de sofisticação e de inovação institucional trazidos pelo NPR e seu paradigma conceitual seria aquele de necessariamente conhecer melhor e alterar (quando necessários) os padrões internos de funcionamento de cada organização do governo. Tal questão permaneceu em grande medida intacta em esforços anteriores de reformas nos EUA, os quais apenas propunham técnicas mais generalistas de controle, planejamento, redução dos custos com a administração, modificações nos sistemas gerenciais sem, no entanto, verificar mais detidamente como o governo funciona e se organiza. O NPR passa a deixar de se preocupar com o que o governo faz (o papel do governo) e ter como prioridade a orientação de como o governo e suas organizações funcionam.

Para os formuladores do NPR, a reinvenção dos mecanismos internos seria uma forma de romper com os padrões históricos de funcionamento marcados pela centralização, reduzida accountability, reduzida conexão dos funcionários com resultados e missões, e outra série de falhas burocráticas. Tal escolha de foco, no entanto, estaria 
profundamente atrelada a reformas mais amplas no balanço de poder e autoridade entre o Executivo e o Legislativo, adicionalmente. Assim, a reinvenção viria a ser um ponto catalizador para tentar promover uma alteração na tensão estrutural no sistema de governança americano entre centralização e descentralização de poder e autoridade entre os poderes. Tal tensão, que permanece viva no sistema de governança americano, origina-se no tempo dos federalistas, refletida nas tensões entre Hamilton (com preferência por maior centralização e controle) e Jefferson (preferência por maior descentralização e self-governance). O modo tradicional de organizar o governo teria sido inspirado no modelo hamiltoniano, privilegiando centralização, estruturas hierárquicas e maior controle do Legislativo sobre o Executivo. O NPR viria tentar resgatar a visão jeffersoniana, a qual se inclina por alternativas e mecanismos que privilegiam descentralização, autonomia, e self-governance, sendo, portanto, uma solução que pende para uma redução da interferência do Legislativo sobre a burocracia. Com efeito, os objetivos programáticos do NPR associam, portanto, eficiência e performance na oferta de serviços públicos a uma revisão nas relações entre Legislativo e Executivo, e ainda a uma capacidade das organizações em ajustar seus mecanismos internos (incentivos) a tais imperativos.

Durante a formulação do NPR, o congresso democrata não foi consultado acerca do programa de reformas administrativas. O único elo institucional entre o Congresso e os formuladores das reformas naquele momento foi a aprovação do Government Performance and Result Act (GRPA) em 1993, uma iniciativa do Legislativo que revela as preferências políticas sobre a questão da performance da administração pública federal. O NPR foi formulado, portanto, sobre os princípios do GRPA, mas, no entanto, considera que os efeitos do Legislativo sobre a burocracia são danosos à performance. O NPR parte do pressuposto que o Congresso, por razões políticas, impõe regras e procedimentos que prejudicam o funcionamento das agências e departamentos do governo em termos de sua capacidade de inovação, de autonomia gerencial, de melhores resultados e de controle de custos. No caso americano, a relação entre o Congresso e a burocracia tem demonstrado que o Congresso contribui em muito para uma administração pública movida pela estrita obediência às regras, as quais desassociam os objetivos organizacionais de questões decisivas como performance, qualidade, resultados e accountability.

Outro ponto central diagnosticado pelos formuladores das reformas foi o excesso de centralização exercido por algumas agências do governo como o General Services Administration (GSA), o Office of Personnel Management (OPM), e o Office of Management and Budget (OMB), agências responsáveis pela centralização e hierarquia acerca dos modos e padrões de prestações dos serviços no sistema de administração pública. 
O papel e as responsabilidades destas agências deveriam ser fundamentalmente revistas com as reformas, sobretudo no que se refere aos seus graus de interferência nas decisões individuais das agências e na definição das prioridades de gastos e controle de custos. ${ }^{9}$

No plano interno das organizações, as propostas de reinvenção focalizaram-se na necessidade de promover incentivos de mercado nas agências e departamentos do governo em áreas específicas, tais como gestão de recursos humanos, uso de tecnologias, compra de material, salários, padrão de prestação de serviços, e.g. Tais incentivos de mercado potencializariam instrumentos necessários para transformar o modo de organização e funcionamento das agências do governo, passando de ambientes "regulados" para ambientes marcados por competição e resultados, em similaridade a firmas privadas operando em ambientes de mercado. Tal transformação estratégica permitiria, por exemplo, que as ações individuais dos funcionários (reguladas por contratos de trabalho) fossem conectadas à performance e eficiência na oferta de serviços para a organização, premiando desempenho individual, inovação, criatividade e performance no desempenho das atividades no trabalho. Os incentivos de mercado viriam, portanto, possibilitar formas de conduzir as organizações a ajustarem suas missões e objetivos organizacionais a resultados e custos, desviando-se das tradicionais formas de estrita obediência às regras. ${ }^{10}$ Com isto, cumulativamente, pretendia-se promover uma mudança significativa na cultura organizacional do setor público.

Caberia, portanto, a cada organização se envolver de modo ativo para a reinvenção dos designs dos incentivos necessários para as diversas agências e departamentos. O novo padrão de incentivos poderia ser altamente produtivo, caso fossem formulados a partir de um esforço coordenado do governo federal com o envolvimento das agências e departamentos, no sentido de detectar e alterar seus padrões de funcionamento e organização, orientando as reformas necessárias. Dada tal condição, cada agência assumiu considerável responsabilidade em cooperação com o governo federal para promover estratégias concretas de realinhamento dos seus procedimentos internos para a reinvenção do governo.

A justificativa para tal forma de concepção e implementação das reformas, num esforço de síntese, ocorre, portanto, por vários fatores combinados. Primeiro, as formas anteriores de concepção e tratamento dos problemas burocráticos haviam mostrado os seus limites de alterar o funcionamento da burocracia. Segundo, tal forma de entender o setor público se associa diretamente às novas formas teóricas dominantes no atual mainstream do pensamento acadêmico na economia, na administração pública e nas políticas públicas, às quais concebem a burocracia e as organizações a partir dos pressupostos da new economics of organization $^{11}$ e do novo institucionalismo econômico, princípios que 
privilegiam a relação entre as instituições (as regras do jogo ou a estrutura de incentivos), a performance e eficiência das organizações. Assim, reinventar o governo inexoravelmente passaria por uma tentativa de rever as "regras do jogo" no interior das organizações. Terceiro, a redução das resistências políticas. A forma fragmentada de condução das reformas teria mais a ver com a deliberada estratégia do governo em ajustar as reformas às especificidades da natureza da política de cada organização, evitando ir de encontro às mesmas. Os princípios gerais do paradigma de administração pública proposto pelo NPR são analisados a seguir.

\subsection{O NPR e o paradigma empreendedorialista}

Os formuladores do NPR partiram do princípio geral de que grande parcela dos problemas e patologias da burocracia federal resultavam de uma crise mais ampla de paradigma, no qual se moldaram as estruturas do governo federal. O diagnóstico da crise de paradigma apontava para a evidência de que princípios e formas tradicionais de organização e de funcionamento da burocracia federal eram pouco compatíveis com as demandas por melhor governo. Para reinventar o governo alterando o modo como este funciona, seria fundamental que as formas gerenciais, os princípios e o modo de organizar a burocracia fossem profundamente alterados através de uma concepção diferente em torno de um novo paradigma para a administração pública.

Baseado nas experiências de reformas em corporações do setor privado, em experiências de reformas em diversos governos locais nos EUA, e numa série de inovações teóricas na administração pública e teoria das organizações a partir dos anos 80, o NPR trouxe consigo a introdução de um novo paradigma para a administração pública: o empreendedorialismo, o qual parte da premissa de que a administração pública pode ser mais eficiente e efetiva com a introdução de mecanismos de mercado na gestão pública. ${ }^{12}$

Em contraposição ao paradigma gerencialista, o paradigma empreendedorialista se assenta na idéia de similaridade nos princípios de organização e funcionamento dos setores público e privado, a qual sinaliza para a possibilidade do setor público de se organizar e funcionar com sistemas gerenciais movidos por resultados, objetivos, e por performance, como fazem as organizações do setor privado em ambientes concorrenciais. O governo e suas organizações podem orientar-se, portanto, por padrões de qualidade, eficiência e resultados. Por outro lado, em organizações funcionando dentro de incentivos de mercado, os funcionários públicos podem ter seus contratos de trabalho acoplando salários à performance, ${ }^{13}$ o que permite que as organizações tenham resultados com seus objetivos organizacionais e missões na estrutura de governo. 
O segundo princípio empreendedorialista informa que as organizações do governo podem funcionar de forma mais eficiente em ambientes competitivos com outras agências, e mesmo com firmas do setor privado. O estímulo à competição impulsiona as agências do governo no sentido de uma definição mais precisa dos serviços a serem ofertados, das suas clientelas, dos custos dos serviços e das formas institucionais necessárias para atingir resultados, e ainda por um uso qualitativamente superior de recursos e tecnologia para a consecução de resultados. O terceiro princípio informa sobre a questão do tamanho do governo, o qual é uma função direta do número de servidores civis empregados em tempo integral (fulltime employees). O último princípio estabelece que a gestão e os gastos das agências do governo federal devem ser necessariamente atrelados às prioridades orçamentárias, restringindo a capacidade da administração pública em elevar deliberadamente os seus gastos.

Uma administração pública empreendedorialista, na visão dos formuladores do NPR, deve perseguir permanentemente os seguintes estados desejados:

a) eliminar procedimentos e regulamentações gerenciais desnecessárias;

b) transformar a cultura organizacional através da descentralização de autoridade e devolução de responsabilidades para as partes mais periféricas da administração;

c) voltar-se para a performance, eficiência e satisfação do consumidor-cidadão;

d) procurar alternativas viáveis para funcionar melhor e custar menos.

O empreendedorialismo do NPR não constitui novidade quando comparado a experiências internacionais. Na realidade, os empreendedorialistas americanos se balizam - porém, com diferenças substanciais no uso dos instrumentos da governança dado as especificidades das estruturas entre os diferentes países - por princípios importados de outras experiências de reformas, partindo de pressupostos e conceitos utilizados nos governos da Nova Zelândia, Austrália e Inglaterra. ${ }^{14}$

No caso americano, em contraste aos casos examinados no quadro abaixo, o setor público assume papel central no processo de rule-steering tanto na dimensão primária da regulação quanto no modo de governança. Este modelo de governança típico do governo americano a partir dos anos 80 não sofre mudanças drásticas. O NPR se volta para dar continuidade a uma concepção de governança em que o setor público tem o papel fundamental de promover uma condução da regras de funcionamento (rule steering regime), evitando implementar soluções radicais de privatização ou expansão excessiva dos mecanismos de mercado, embora considere-os fundamentais. Para os empreendedorialistas, o papel do governo se mostra ingrediente essencial na organização dos mercados. 
Quadro 1: EUA, Inglaterra e Nova Zelândia. Regimes de governança e mecanismos regulatórios 1980-1993

\begin{tabular}{|c|c|c|}
\hline Regulação & Inglaterra & Nova Zelândia \\
\hline Primária & mercados privatização & mercados privatização \\
\hline Secundária & competitividade & competitividade \\
\hline Terciária & steering results & steering results \\
\hline \multirow[t]{2}{*}{ Tipo de Governança } & setor privado & setor privado \\
\hline & regimes de mercado & regimes de mercado \\
\hline
\end{tabular}

Neste sentido, pode ser explicado por que o NPR assume traço distintivo em relação às experiências desencadeadas por Reagan nos EUA ou por Thatcher na Inglaterra, nas quais as privatizações e a apologia ao setor privado assumem o comando das iniciativas. Os formuladores da reinvenção reconheceram a importância e a necessidade do papel do governo nas sociedades organizadas pelo mercado, assumindo um perfil mais nitidamente institucionalista ao assumir a idéia de que as instituições representam elementos necessários para a eficiência dos mercados e dos governos. O empreendedorialismo se volta, portanto, para reinventar os mecanismos internos de funcionamento da burocracia como princípio, afastando-se de concepções que teorizam sobre os males da presença do governo e dos seus padrões. O NPR combate os excessos de regulação do Legislativo sobre a burocracia e mostra que o ajuste entre organizações e incentivos tem profunda conexão com accountability e eficiência.

\subsection{Exemplificando a reinvenção dos incentivos da burocracia: os laboratórios de reinvenção}

Uma das principais inovações institucionais trazidas pelo NPR foi a criação dos laboratórios de reinvenção, organizações criadas no interior de cada agência, no sentido de promover os mecanismos necessários para o melhor funcionamento das organizações. Os laboratórios representaram as experiências-piloto responsáveis pelo design e ajuste do processo de alteração dos incentivos no interior de cada instância do governo. O governo federal estimulou de modo ativo a formação destas organizações, premiando as inovações e os resultados obtidos por cada organização dentro do programa de reformas. Estas organizações, formadas por gerentes, funcionários e membros do governo federal, foram o locus para a difusão de processos de inovação e recriação dos padrões tradicionais, da postura das agências com relação a resultados, qualidade, performance, e ainda uma forma organizacional em que os membros da reinvenção poderiam mais participativamente entender, lidar e propor reformas adequadas às especificidades — culturais e organizacionais — de cada 
organização. Os labs têm ainda um papel relevante na permanente avaliação, monitoramento e discussão dos resultados obtidos com as reformas, sem perder de vista os objetivos de redução de custos e melhor funcionamento. Tais laboratórios foram pensados como estruturas permanentemente ativas para introduzir inovações nas estruturas internas de incentivos, mudanças na cultura organizacional das agências, descentralização, empowerment, realinhamento dos objetivos organizacionais e missão das agências, e, fundamentalmente para transformar os padrões de prestação dos serviços de atendimento ao consumidorcidadão. ${ }^{15}$

Os laboratórios de reinvenção seriam, portanto, a marca registrada do estilo difuso e fragmentado das reformas no contexto do NPR. Entrar com precisão para alterar e ajustar os mecanismos internos, missões, prioridades, objetivos organizacionais representou per se uma mudança radical na concepção centralizada e hierárquica de lidar com a burocracia e seus problemas nos EUA.

Como afirmam alguns autores, a noção da permanente geração de inovações pelos gerentes no front-line, no sentido de melhorar a qualidade dos serviços prestados pelas agências do governo, foi fundamental para garantir o feedback necessário entre incentivos e performance. Esta concepção se mostra incompatível com esquemas centralizados de comando e estruturas verticalizadas de autoridade, pontos que o governo federal visava fundamentalmente eliminar com a reinvenção. Por outro lado, o maior conhecimento interno acerca das regulações necessárias ao funcionamento das organizações seria um grande passo para que as "regulações desnecessárias" fossem eliminadas. Neste sentido, os laboratórios de reinvenção foram criados estrategicamente no sentido de minimizar interferências de controle central sobre as reformas. $\mathrm{O}$ grande risco dos laboratórios seria o grau elevado de fragmentação, o qual seria problemático em termos de accountability, caso o governo federal não permitisse meios para coordenar o amplo volume de mudanças geradas por todos os laboratórios.

\section{Implementando a reinvenção}

\subsection{A seqüência das reformas}

A primeira fase do NPR, conhecida na literatura temática como o Rego I, foi concebida para implementar as seguintes iniciativas no interior das agências e departamentos do governo: downsizing: ${ }^{16}$ descentralização de funções e de autoridade; desregulamentação interna e alteração dos padrões de prestação de serviços para o consumidor final.

No plano da implementação, este conjunto de atividades se voltou 
se refere a padrões de atendimento ao consumidor, para a criação dos laboratórios de reinvenção, e ainda a formação de conselhos interagências, os quais seriam responsáveis por um sistema de monitoramento de informações para o acompanhamento de 1.250 iniciativas de reinvenção de naturezas diferentes nas diversas agências e departamentos do governo na sua fase inicial, a qual seria fundamental para elevar a accountability e performance do programa.

No que diz respeito às iniciativas de downsizing, o Rego I focalizou, na implementação de iniciativas em cortes de pessoal, a redução de procedimentos e regulações intraburocráticas em 50\%, e ainda a introdução de princípios e padrões para a prestação geral de serviços públicos pelas diversas agências do governo. ${ }^{17}$ As primeiras recomendações sinalizaram para a redução de 252 mil funcionários federais, ${ }^{18}$ e redução estimada dos custos com o governo em torno de \$108 bilhões.

No período 1995-1999, a redução de custos com o governo foi planejada a partir de quatro áreas de reinvenção: cortes em programas governamentais; redução de pessoal; ${ }^{19}$ desregulamentação interna; mudanças na cultura organizacional; introdução de mecanismos de mercado no interior da burocracia e implementação de tecnologias de informação. As metas programadas para a redução de custos por natureza de reforma estão apresentadas no Gráfico 2 abaixo. Os dados revelam que as iniciativas de alterações de padrões internos de incentivos, desregulamentação e mudanças internas nas agências e departamentos deveriam produzir a grande parcela das reduções de custos programados com as reformas.

\section{Gráfico 2: NPR - Estimativa de redução dos custos por natureza de reforma}

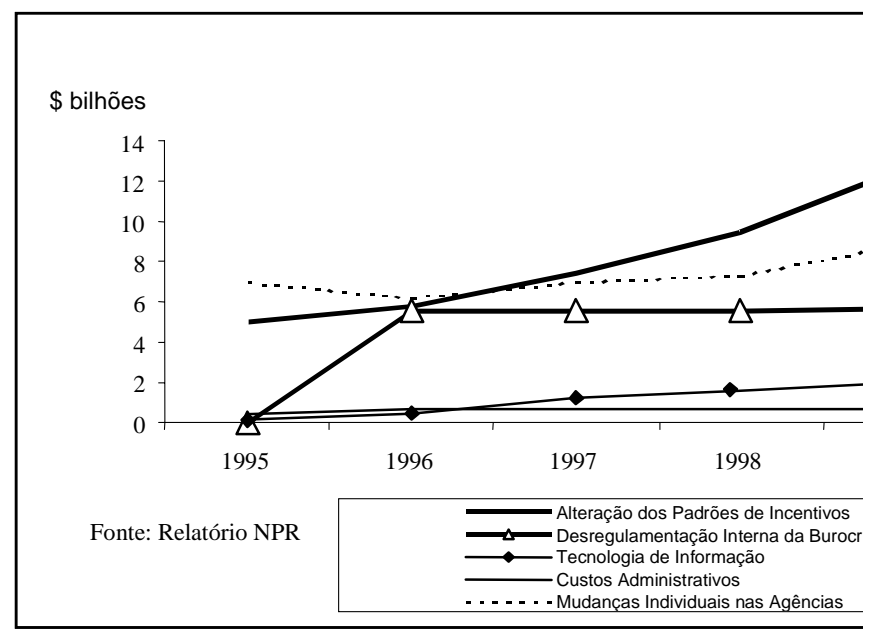


No que tange a concepção da redução dos custos com o governo, estaria claro para os formuladores do programa que, no médio e longo prazo, os resultados efetivos das reformas dependeria em grande parte do grau de compromisso das agências ao programa proposto. Ajustes graduais e novas recomendações seriam de fundamental importância ao longo do processo dando o ajuste fino qualitativo (fine-tunning) das reformas, sobretudo aquelas de natureza menos tangível, como as mudanças nos processos, incentivos e cultura organizacionais. A redução dos custos com o governo deveria ocorrer a partir da contínua reinvenção das estruturas de incentivos internas e comuns às agências e não apenas a partir de uma simples execução das recomendações formuladas pelo programa.

No sentido de apreender como o NPR pretendeu atingir a redução de custos, é importante compreender como os formuladores do programa pretenderam fazê-lo ao longo do tempo. Considerando todas as agências no período 1996-2000 — a segunda fase do programa Rego II — como apresentado no gráfico abaixo, a redução dos gastos públicos apresentaria três fases a saber: a primeira, que compreende o período de 1996 a 1998, em que as reformas produziriam, caso bem-sucedidas, uma agressiva redução dos gastos públicos. O período 1998-1999 seria estável, seguindo-se de uma nova redução agressiva de custos.

\section{Gráfico 3: Redução estimada dos gastos do} governo 1996/2000 (Todas as agências)

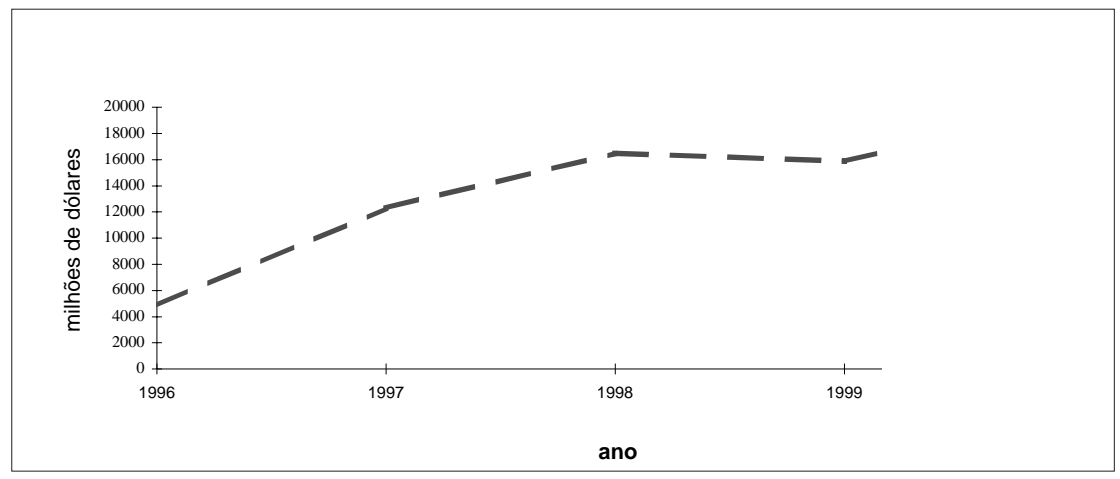

\subsection{A segunda fase da reinvenção: quando as reformas encontram as exigências da política}

No segundo relatório lançado em 1994, Putting Costumers First: standards for serving for the american people, o objetivo programático de funcionar melhor assumiu as principais iniciativas da agenda de reformas, dando continuidade às preferências da primeira fase. $\mathrm{O}$ governo federal havia conduzido o plano tático das reformas, estimulando as 
agências a trabalharem intensivamente numa mais precisa definição dos seus padrões de prestação de serviços, na alteração dos incentivos internos e na promoção de difusão de poder e autoridade para os níveis mais de ponta da organização.

Tal concepção teria uma forte dose de estratégia política. O governo Clinton pretendia utilizar suas energias iniciais num forte esquema de "incentivos" para o empowerment das agências, de combate ao red tape, e desregulamentação da burocracia, fazendo com que a visibilidade e o envolvimento das partes do sistema federal se motivassem em torno dos objetivos programáticos do NPR num primeiro momento. Deliberadamente, o governo partiria para políticas de reinvenção da cultura organizacional e das estruturas de incentivos internos como o primeiro golpe tático, o qual criaria o ambiente necessário para a implementação dos cortes previstos de pessoal e dos custos, que viriam inevitavelmente na segunda fase da reinvenção.

Por outro lado, ao proceder num esforço primeiro em explorar as possibilidades de fazer com que o governo funcionasse melhor, os estrategistas em Washington pretendiam minar possíveis resistências internas às mudanças, ajustando as reformas ao modo específico de como cada organização cooperaria com as mudanças, o que em muito dependeria de como "a política" das reformas se processaria no plano individual de cada uma das agências e departamentos do governo.

No terceiro relatório do NPR, o Common Sense Government (1995), o governo federal introduziu mais 180 recomendações novas para as reformas. Neste relatório, os formuladores do programa difundem a noção de que as reformas propostas pela administração Clinton seriam o modo consensual pelo qual os agentes políticos e administrativos deveriam posicionar-se em relação à reinvenção do governo. Este momento seria crucial para a administração Clinton e o seu programa de reformas, uma vez que o novo Congresso eleito provavelmente exigiria maior agressividade no combate aos custos com o Executivo, como prometidos pelo governo Clinton. Certamente, as tensões políticas seriam decisivas nesta fase delicada das reformas.

A visão de que a reinvenção do governo representaria um consenso para os atores políticos no Executivo, no Legislativo e em outras organizações de relevância (sindicatos, partidos, etc) seria apenas um rótulo estratégico para aliviar a batalha política entre o Executivo e o Legislativo, que viria ocorrer quanto ao encaminhamento e as preferências em torno da condução das reformas do governo, e sobretudo, em relação aos cortes dos custos do governo. Até então, a administração Clinton e os estrategistas do programa de reinvenção teriam optado pela estratégia de implementar o politicamente realizável, sem procurar criar fortes tensões com o poder Legislativo, sobretudo porque as reformas pretendiam 
alterar o modo de relacionamento entre os poderes Legislativo e Executivo. Dado que no fundo das propostas do NPR estava explícito a ampliação da autonomia das agências administrativas, o novo Legislativo poderia criar poderosas resistências à aprovação de legislação necessária para implementar as reformas pretendidas.

O primeiro round da batalha política entre o Legislativo e os formuladores do programa em Washington se tornou claro já em 1993, no momento da definição das prioridades para o orçamento nacional, e continuou de modo decisivo em 1995. Passados dois anos do início do programa, em 1995, contrariamente às expectativas dos formuladores do programa, apenas 66 das 280 recomendações propostas pelo programa haviam sido aprovadas pelo Congresso; $70 \%$ das propostas de legislação relacionadas com a reinvenção estavam pendentes, demandando significativo esforço político. O montante correspondente a este conjunto de legislações representou, segundo relatórios oficiais, US\$ 58 bilhões.

O apoio do Congresso de maioria democrática, sobretudo na primeira fase do programa, não se mostrou verdadeiro. Ironicamente, na aprovação do orçamento do ano fiscal de 1993, o Congresso apenas aprovou uma tímida porção dos cortes propostos:

"A batalha na definição do orçamento de 1993 ajudou a definir o resultado das tensões internas do programa. Os senadores seguraram os votos decisivos para aprovar os proposals da administração no orçamento. As barganhas da administração com os membroschave do Congresso colocaram algumas das idéias de money-saving do programa de lado. ... Como resultado, o fantasma da redução do déficit inibiu qualquer promessa de transferir poder para os funcionários no sentido de melhoria da performance. ... Na realidade havia um conflito interno entre os objetivos de work better and cost less (...) durante o primeiro ano dos cortes de pessoal, 2/3 destes vieram do departamento de Defesa (...). Algumas outras agências atingiram pequenas reduções de suas despesas. ...Em outubro de 1993, a administração condensou algumas de suas reformas no proposal H.R. 3400, conhecido como o Government Reform and Savings Act. A administração estimou que tal proposal poderia produzir US\$ 6 bilhões em redução de custos nos próximos cinco anos. Entretanto, o Congressional Budget Office revisou a proposta do governo, e estimou que a redução dos custos deveria ser de apenas $\$ 2.5$ bilhões, quantidade menor do que a metade do que o pretendido pela administração" (KETTL, 1995). ${ }^{20}$

Apesar dos esforços internos das agências para reinventar incentivos e a cultura organizacional das agências, tais medidas, por natureza, 
demandam um longo tempo para sedimentação e apresentam pouca visi-

bilidade nos resultados atingidos. Dado que a visibilidade política do governo Clinton em um ambiente marcado por mudanças no Legislativo e as preferências políticas em torno das reformas se alteraram de modo radical: downsizing e combate aos custos com o governo passaram a ser a prioridade do NPR. Tal preferência era coincidente com alguns dos formuladores mais radicais em Washington, os quais pressionavam o presidente com o argumento de que sem a redução do tamanho do governo o NPR seria apenas mais um programa na história das reformas federais nos EUA, e um provável malogro seria o cenário mais provável. Apesar dos ganhos que adviriam com as mudanças na cultura organizacional, no médio e longo prazo, o processo de cortes no tamanho do governo mostraria uma dimensão inevitável das reformas. As mudanças na cultura organizacional e desregulamentação das agências não gerariam os efeitos-demonstração necessários no curto prazo para assegurar o objetivo programático de fazer com que o governo custe menos. Com a vitória tática das forças de downsizing, o dilema passou a ser o de como realizar os cortes. A questão decisiva para os estrategistas pode ser resumida do seguinte modo: onde cortar o governo para que ele funcione melhor e gaste menos, com maiores benefícios do ponto de vista político no apoio às reformas no Congresso?

Tal questão viria a assumir mudanças drásticas na agenda de reformas, sobretudo considerando a possibilidade de que o novo Congresso seria republicano, dado que historicamente as bancadas partidárias se alternariam no meio de cada governo, independente do partido no poder. ${ }^{21}$ A partir de novembro de 1994, momento em que o novo Legislativo seria eleito segundo as regras do jogo no sistema de governança nos EUA, o principal objetivo do governo quanto às reformas administrativas seria fazer valer a promessa de cortes significativos nas despesas do governo, abolindo departamentos, reduzindo o número de funcionários e uma série de conhecidas estratégias de downsizing. Pela primeira vez, a capacidade política do governo seria testada para fazer valer suas intenções de reinventar o governo.

\subsection{O novo Congresso e a reinvenção do governo}

A mudança das preferências na segunda fase das reformas está fundamentalmente atrelada ao novo ambiente político que se configurou a partir de 1995. O novo Congresso republicano, marcadamente disposto a maior agressividade na redução do tamanho do governo, viria a exigir mais esforços do presidente e de seu programa em torno da redução dos custos com o governo. A materialização institucional da posição de maioria republicana no Legislativo em torno das reformas se deu com a agenda 
montada em torno do Contrato com a América (Contract with America), um programa republicano visando restringir o papel e o poder do governo federal, estimulando privatização de funções e devolução de poder e autoridade para os estados e governos locais como alternativa para as reformas do governo federal.

As preferências políticas dos republicanos em torno das reformas no interior do Congresso se materializaram com a elaboração do conhecido Horn Report (HR), formulado pelo congressista Stephen Horn do estado da Califórnia, o qual assumiu o papel de presidente do Subcommitee on Government Management, Information, and Technology, criado em substituição ao House Committee on Government Reform and Oversight, o qual ficou responsável pelas principais decisões em torno das reformas administrativas no Congresso anterior. O novo subcomitê responsável pelas reformas, o qual representa institucionalmente o locus do conflito político em torno das reformas administrativas, como se verá adiante de modo mais detalhado, era de maioria republicana, juntamente com uma minoria de 23 democratas. A fragmentação das preferências políticas em torno da questão se dividiu em duas posições bastante claras e conflituosas: os republicanos apoiavam as recomendações e as linhas programáticas do Horn Report, e os democratas defendiam as do NPR.

Logo no início do ano de 1995, o subcomitê tomou a decisão de realizar um completo reexame da administração federal, na qual figuraria uma completa revisão do NPR. Paradoxalmente, os republicanos passaram a defender uma posição em apoio a uma maior centralização, controle e hierarquização da administração pública, em diametral contraste às posturas do programa original de reinvenção. Assim, configurou-se institucionalmente o grau de conflito em torno do programa. O sinal dado pelos republicanos de oposição ao NPR, em uma leitura mais detalhada, seria uma forma indireta de mostrar ao presidente e seus estrategistas o descontentamento com a lenta tomada de decisão em relação às políticas mais agressivas em relação aos custos do governo. Por outro lado, tradicionalmente, os republicanos têm como preferência política uma visão hamiltoniana de governo, na qual o Executivo deve ser controlado de modo mais centralizado, do que a visão jeffersonniana de self-governance e descentralização. Uma descrição panorâmica do mapa de preferências políticas reveladas pelos dois grupos citados no subcomitê em torno das reformas é apresentada no quadro a seguir. 


\section{Quadro 2: Preferências políticas em 1995 para a reforma administrativa}

\begin{tabular}{|c|c|c|c|}
\hline Dimensão & Questão central & Preferências do HORN Report (republicanos) & Preferências do NPR (democratas) \\
\hline Constitucional & $\begin{array}{l}\text { Quem deve ser responsável pela } \\
\text { administração federal, em que } \\
\text { aspectos, e de que modo? }\end{array}$ & $\begin{array}{l}\text { Ampliação do controle centralizada do Congresso e da } \\
\text { Presidência sobre a administração federal. } \\
\text { Administração por "obediência às regras", e pela manutenção } \\
\text { de estruturas hierárquicas. } \\
\text { Crítica à abordagem ad hoc e instável proposta do NPR. } \\
\text { A missão e papel do governo como questão central na reforma. }\end{array}$ & $\begin{array}{l}\text { Centralização reduz capacidade gerencial e performance. } \\
\text { Associa devolução de autoridade com a estratégia para } \\
\text { obtenção de resultados. }\end{array}$ \\
\hline Econômica & $\begin{array}{l}\text { Como a administração pública pode } \\
\text { ser reorganizada de modo a se ajustar } \\
\text { aos novos imperativos econômicos? }\end{array}$ & $\begin{array}{l}\text { Equilíbrio do Orçamento Público como justificativa econômica } \\
\text { para as reformas.. }\end{array}$ & $\begin{array}{l}\text { Reduzir custos com o governo eliminando posições sem } \\
\text { referência com missão ou papel do governo. } \\
\text { Recuperar poupança e investimento público via cortes no } \\
\text { governo como justificativa econômica das reformas. }\end{array}$ \\
\hline Política & $\begin{array}{l}\text { Qual o número apropriado e papel dos } \\
\text { political appointees na administração } \\
\text { pública? }\end{array}$ & $\begin{array}{l}\text { Political appointees no alto escalão da administração produz } \\
\text { reduzidos ganhos de expertise para a administração pública. } \\
\text { Fortalecimento de programas de carreiras na administração federal. } \\
\text { Propõe redução drástica do número de political appointees. }\end{array}$ & $\begin{array}{l}\text { Redução dos cargos de carreira na administração federal. } \\
\text { Aumento de poder e controle dos political appointees aliado a uma } \\
\text { maior autonomia dos funcionários nas instâncias de contato direto } \\
\text { com os usuários e clientes das agências do governo. }\end{array}$ \\
\hline $\begin{array}{l}\text { Uso de Tecnologia } \\
\text { de Informação }\end{array}$ & $\begin{array}{l}\text { Como promover uma revolução } \\
\text { tecnológica na administração pública? }\end{array}$ & $\begin{array}{l}\text { Ampliação do papel do Office of Management na gestão e } \\
\text { coordenação centralizada do uso de tecnologia de informação } \\
\text { nas agências e departamentos. } \\
\text { Accountability na gestão e coordenação da informação não } \\
\text { necessariamente associadas à difusão de autoridade e } \\
\text { descentralização. } \\
\text { Uso estratégico de tecnologias de informação visando atingir } \\
\text { objetivos como a redução de instâncias e tempo na tomada de } \\
\text { decisão no interior da burocracia. } \\
\text { Desenvolver práticas gerenciais integradas voltadas para } \\
\text { medição da performance do governo. }\end{array}$ & $\begin{array}{l}\text { Accountability na gestão e coordenação da informação } \\
\text { associadas à difusão de autoridade e descentralização. } \\
\text { Uso estratégico de tecnologias de informação visando atingir } \\
\text { objetivos como redução de instâncias e tempo na tomada de } \\
\text { decisão no interior da burocracia. } \\
\text { Desenvolver práticas gerenciais integradas voltadas para a } \\
\text { medição da performance do governo. }\end{array}$ \\
\hline $\begin{array}{l}\text { Cultura } \\
\text { Organizacional }\end{array}$ & $\begin{array}{l}\text { Que atitudes e valores devem ser } \\
\text { considerados mais relevantes de modo } \\
\text { a melhorar a administração federal? }\end{array}$ & $\begin{array}{l}\text { Compromisso e lealdade. } \\
\text { Missão e papel do governo como norteadores da reforma. } \\
\text { Forte apoio ao desenvolvimento de carreiras na burocracia } \\
\text { federal. }\end{array}$ & $\begin{array}{l}\text { A questão central é como o governo funciona e não o que o } \\
\text { governo faz. } \\
\text { Estímulo ao corte de posições e cargos independentes do papel } \\
\text { do governo. } \\
\text { Estímulo à descentralização e devolução de autoridade para as } \\
\text { instâncias mais periféricas da burocracia. }\end{array}$ \\
\hline $\begin{array}{l}\text { Organização da } \\
\text { Gestão Federal }\end{array}$ & $\begin{array}{l}\text { Qual será a melhor forma de } \\
\text { organização e gestão para o governo } \\
\text { federal? }\end{array}$ & $\begin{array}{l}\text { Controle presidencial na gestão do governo federal. } \\
\text { Apoio à posição tradicionalmente da administração pública. } \\
\text { Combate a problemas de duplicação e superposição de } \\
\text { atividades e responsabilidades entre departamentos e agências. } \\
\text { Alinhamento e consolidação de programas das agências } \\
\text { federais por objetivos. }\end{array}$ & $\begin{array}{l}\text { Despreocupação com estruturas organizacionais. } \\
\text { Esforços para uma mudança fundamental na cultura e nos } \\
\text { processos gerenciais internos às agências. }\end{array}$ \\
\hline
\end{tabular}

Fonte Carrol and Lynn (1996). 
A resposta dos democratas à posição republicana de rever o NPR se deu de imediato, quando a minoria democrática composta por 19 membros de um total de 23 democratas assinou um documento no Committee on Government Reform and Oversight, propondo uma abordagem alternativa à posição do HR, e defendendo de modo ativo a posição do NPR. Assim consolida-se politicamente a estratégia do NPR de orientar o serviço público por padrões de melhor qualidade na oferta de serviços, de evitar interferência excessiva do Legislativo na burocracia, de garantir descentralização, revisão dos incentivos internos das agências e departamentos do governo, entre outros pontos de interesse. A posição da minoria democrática converge para a hipótese de que a centralização e hierarquização burocrática representam elementos nocivos à eficiência e accountability na administração do governo. A qualidade da administração pública requer fundamentalmente uma descentralização de autoridade para o Executivo, sobretudo para os gerentes públicos e funcionários nas instâncias mais periféricas do governo.

Tais tensões no plano da política, no entanto, fariam com que o programa finalmente se voltasse para um maior combate às estratégias de downsizing. ${ }^{22}$ Ao assumir esta preferência para conduzir as reformas ${ }^{23} \mathrm{O}$ governo Clinton entra numa mais trama complexa: o aprofundamento dos cortes no governo poderiam, no curto prazo, gerar incentivos perversos para a qualidade no funcionamento da administração federal.

Especificamente, os cortes de pessoal poderiam fazer com que os melhores e mais qualificados funcionários federais, sobretudo os de natureza political appointee, pudessem rapidamente migrar para outros cargos no setor privado, reduzindo a capacidade do governo em funcionar melhor, paradoxalmente. Anunciando um programa agressivo de downsizing, o governo poderia, paradoxalmente, entrar numa progressiva redução de sua capacidade de funcionar melhor.

Contudo, o objetivo de reduzir o tamanho do governo se tornou o foco central do NPR na fase Rego II. Os cortes no governo poderiam ter impacto no Legislativo para aprovação das reformas num congresso de maioria republicana, garantindo ainda a visibilidade do programa, e ampliando as margens políticas de reeleição. $\mathrm{O}$ ano eleitoral, o novo congresso e as tensões internas acerca das reformas administrativas seriam os fatores decisivos para a mudança de preferências. A escolha política por downsizing seria, por outro lado, justificada a partir dos interesses do presidente Clinton em garantir a reeleição. O ideário de encolher o governo a todo custo seria uma poderosa arma para conseguir o apoio eleitoral, tal qual o fizera em 1992 no plano do discurso, o candidato presidencial, Ross Perot, conseguindo aproximadamente $19 \%$ dos votos nas eleições presidenciais. 


\section{Acessando resultados do programa}

Nesta seção são apresentados alguns resultados da implementação das reformas, em algumas variáveis de interesse, tais como: efetividade na redução dos gastos públicos; redução do número de funcionários federais (nas categorias Schedule $C$ e non-career); número e redução do número de political appointees nas agências do governo. Uma compreensão do comportamento destas variáveis nos permitirá realizar comparações no tempo entre o NPR e outras experiências de reforma nos EUA, e ainda, comparações entre agências e departamentos do governo em torno dos resultados obtidos em áreas específicas das reformas.

Quadro 3: NPR - Efetividade na redução dos gastos por agência e departamento em 1996

\begin{tabular}{|c|c|c|c|}
\hline $\begin{array}{l}\text { NPR — Efetividade na redução de gastos } \\
\text { por departamento e agências (ano 1996) }\end{array}$ & $\begin{array}{l}\text { Redução } \\
\text { estimada }\end{array}$ & $\begin{array}{c}\text { Redução } \\
\text { efetiva }\end{array}$ & Efetividade \\
\hline Agriculture & 148 & 0 & $0 \%$ \\
\hline Commerce & 16 & 51 & $319 \%$ \\
\hline Education & 113 & 109 & $96 \%$ \\
\hline Energy & 820 & 1.673 & $204 \%$ \\
\hline Health and Human Services & 15 & 0 & $0 \%$ \\
\hline Interior & 29 & 6 & $21 \%$ \\
\hline Labor & 40 & 0 & $0 \%$ \\
\hline Transportation & 2.845 & 25 & $1 \%$ \\
\hline Treasury & 112 & 619 & $553 \%$ \\
\hline Veterans Affairs & 11 & 0 & $0 \%$ \\
\hline Corps of Engineers & 29 & 0 & $0 \%$ \\
\hline Federal Emergency Management Agency & 34 & 0 & $0 \%$ \\
\hline $\begin{array}{l}\text { National Aeronautics and Space } \\
\text { Administration }\end{array}$ & 226 & 226 & $100 \%$ \\
\hline National Science Foundation & 104 & 103 & $99 \%$ \\
\hline National Business Administration & 230 & 143 & $62 \%$ \\
\hline Interstate Commerce Commission & 4 & 4 & $100 \%$ \\
\hline Federal Deposit Insurance Corporation & 79 & 0 & $0 \%$ \\
\hline $\begin{array}{l}\text { Chemical Safety and Hazard } \\
\text { Investigation Board }\end{array}$ & 1 & 1 & $100 \%$ \\
\hline AllAgencies & 4.856 & 2.960 & $61 \%$ \\
\hline
\end{tabular}

Fonte: Relatórios do NPR (Elaboração do autor) 
Para uma primeira tentativa de avaliar a efetividade do programa em termos das agências e departamentos, procedeu-se a uma quantificação do objetivo central do NPR: a redução dos custos. A questão central aqui foi perguntar como e em que intensidade cada departamento e agência do governo havia, num período de tempo significativo em relação ao início do programa, conseguido reduzir os custos de acordo com as metas programáticas. Para tal avaliação, procedeu-se a uma comparação da redução estimada (proposta pelos formuladores do programa) e a redução efetiva (consolidada em cada agência, segundo dados oficiais do OMB). O quociente entre a redução efetiva e a estimada nos fornece a efetividade por agência. A efetividade global do programa foi considerada como a relação entre o total entre as mesmas variáveis para o total das agências.

Os dados apresentados revelam uma profunda diferenciação em torno dos resultados atingidos. Isto revela que a redução dos custos tem a ver com as especificidades dos universos políticos e organizacionais de cada uma das organizações do governo. Tal evidência revela, de modo bastante aproximado, como e por que o NPR tentou perseguir uma estratégia fragmentada de reformas. A alta variabilidade das agências e as iniciativas de redução de custos revelam, por outro lado, o grau de cooperação e resistência à mudança. Em termos gerais, considerando todas as agências e departamentos do governo, a efetividade na redução dos gastos no ano de 1996 foi de $61 \%$, mostrando que passados três anos, pouco mais do que a metade do estimado pelos estrategistas em Washington, havia ocorrido no mundo real. Alguns departamentos, como Agriculture, Health and Human Services (HHS), Labor, Veterans Affairs, Corps of Engineers, e outras agências menores mostraram uma nula redução dos gastos, revelando uma indiferença aos programas de redução de custos neste ano. Por outro lado, departamentos como Commerce, Energy e Treasury mostraram elevadíssima efetividade, superando em muito as expectativas dos programas. Algumas agências como a NASA e o Interstate Commerce Commission apresentaram efetividade 100\%, correspondendo às expectativas do governo federal.

Após esta breve avaliação dos resultados relativos à redução dos custos, partiremos para avaliar os resultados obtidos pelas reformas no seu propósito de reduzir do número de funcionários. Os dados apresentados no gráfico 4 abaixo mostram que a redução de funcionários revela uma tendência histórica das várias administrações americanas desde o ano de 1970. Contudo, os dados mostram claramente que após a implementação do NPR, o número de funcionários full-time declina para um ponto mínimo em 1995, mostrando que o NPR apresentou uma maior capacidade de levar a cabo a tarefa de reduzir a força de trabalho no governo federal do que outras experiências de reformas. 
Gráfico 4: EUA - Evolução do número de funcionários

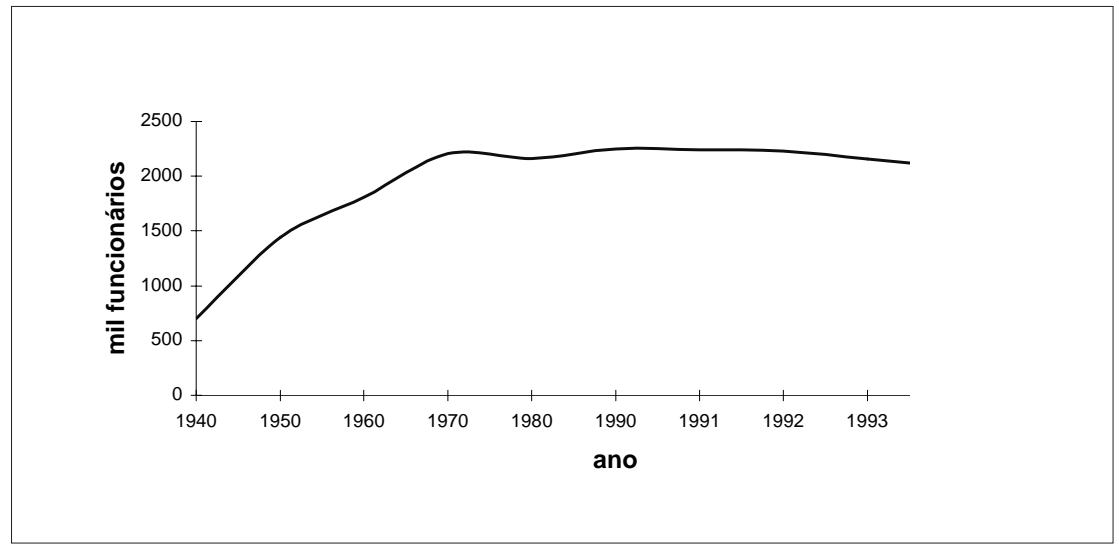

Uma análise mais cuidadosa da questão da redução do número dos funcionários requer a compreensão do fator político no crescimento do setor público federal. Para muitos analistas da administração federal americana isto tem a ver com o alto escalão da burocracia, o qual tem um número expressivo de political appointees,${ }^{24}$ fazendo com que os custos com o governo sejam elevados de modo considerável. Por outro lado, o número de political appointees revela em que medida as diversas instâncias da burocracia são dependentes dos ambientes políticos. Utilizamos aqui o número de political appointees nos diversos departamentos e agências do governo para interpretar o fenômeno de como o NPR conseguiu lidar com a dimensão política da burocracia. No sentido de permitir uma comparação dos resultados entre diferentes administrações, analisaremos as três gestões da década de 80: Reagan (1981-1989), Bush (1989-1993) e a gestão Clinton, no sentido de verificar a efetividade do governo em reduzir duas categorias específicas de political appointees: os Non-Career Senior Executive Service (SES) ${ }^{25}$ e o Schedule $C^{26}$ no nível de todas as agências e departamentos do governo.

Os dados revelam que o governo Clinton com o seu programa de reformas conseguiu manter estável o nível dos funcionários SES, fato que não havia sido verdadeiro para as administrações Reagan e Bush, evidenciando o argumento de que o NPR conseguiu ser mais efetivo em sua relação com o universo político no que se refere a esta questão específica do que as experiências anteriores de reforma. 
Gráfico 5: Funcionários non-career por administração (Reagan, Bush e Clinton)

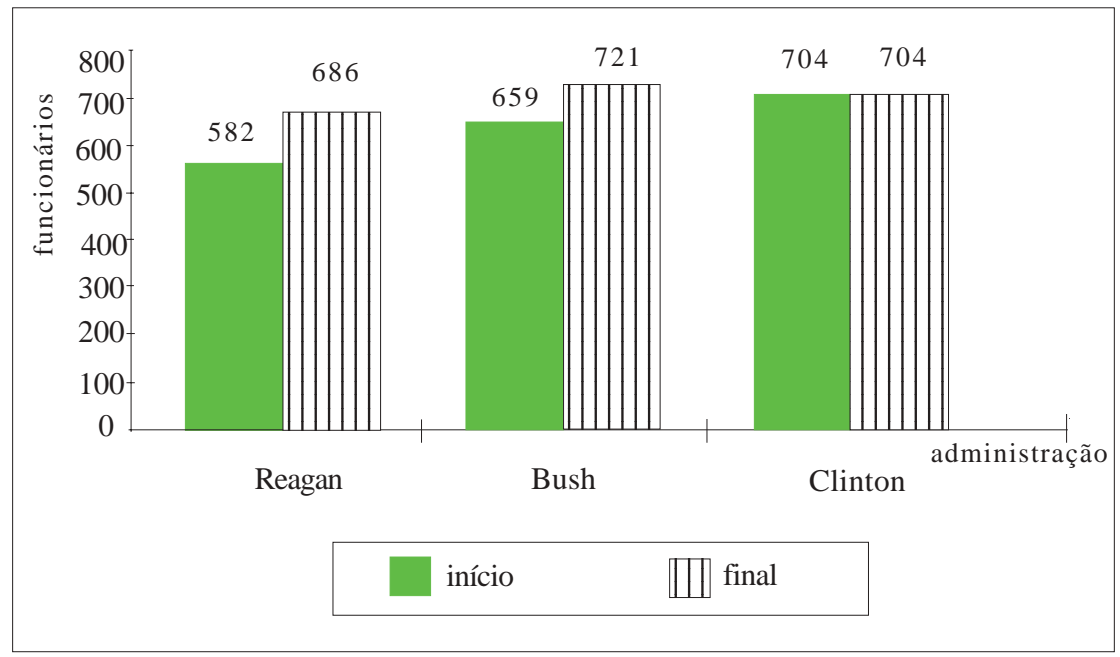

Quando os dados relativos à redução dos SES por administração são desagregados nos principais departamentos e agências do governo americano, o que se verifica são as seguintes evidências: primeiro, a alta variabilidade dos resultados entre agências e departamentos, revelando o intenso grau de diversidade no que se refere à cooperação com a implementação das reformas. Isto revela, em grande medida, como os diferentes "universos políticos" de cada uma destas organizações responde às reformas propostas pelo governo federal; segundo, numa perspectiva comparativa simplificada, os dados revelam que a administração Reagan conseguiu em sua gestão reduzir em apenas três agências - Energy (-12 funcionários ), Labor (-1 funcionário), e Veterans Affairs (-2 funcionários) - ao mesmo tempo que os departamentos de Defesa, Justiça e Agricultura aumentaram significativamente o número de SES. A gestão Bush conseguiu reduzir o número de SES em sete departamentos. No NPR no entanto, apenas seis agências sofreram redução no número de SES. 
Quadro 4: Redução dos funcionários non-career por administração e por agência

\begin{tabular}{|l|c|c|c|}
\hline Agency & $\begin{array}{c}\text { Reagan } \\
\mathbf{1 9 8 0 / 1 9 8 3}\end{array}$ & $\begin{array}{c}\text { Bush } \\
\mathbf{1 9 8 8} / \mathbf{1 9 9 1}\end{array}$ & $\begin{array}{c}\text { Clinton } \\
\mathbf{1 9 9 2 / 1 9 9 4}\end{array}$ \\
\hline Agriculture & 13 & 6 & -9 \\
\hline Commerce & 2 & -4 & 12 \\
\hline Defense & 28 & 16 & 16 \\
\hline Education & 1 & 4 & 1 \\
\hline Energy & -12 & 19 & -4 \\
\hline EPA & 5 & 6 & 3 \\
\hline General Service Administration & 9 & 8 & -7 \\
\hline HHS & 6 & 14 & 0 \\
\hline HUD & 8 & -1 & 6 \\
\hline Interior & 4 & 0 & -7 \\
\hline Justice & 27 & 1 & -6 \\
\hline Labor & -1 & -3 & 9 \\
\hline NASA & 8 & -1 & 0 \\
\hline OMB & 5 & -5 & 3 \\
\hline OPM & 6 & -5 & 2 \\
\hline State & 5 & 12 & -5 \\
\hline Transportarion & 4 & -3 & 2 \\
\hline Treasury & 3 & 0 & 7 \\
\hline Veterans Affairs & -2 & 0 & 0 \\
\hline All Agencies & 62 & \\
\hline
\end{tabular}

Fonte: OMB (1995). Budget of the United States Government: Historical Tables. Washington D.C.

Quando comparados os dados relativos aos funcionários do tipo Schedule $C$, como será mostrado no gráfico a seguir, observa-se que existe na gestão Clinton uma reversão da tendência das gestões anteriores, qual seja de redução significativa no número de political appointees nesta categoria específica de funcionários.

Quando observados os dados oficiais relativos aos Schedule $C$ no nível dos principais departamentos e agências do governo, verifica-se que tanto a gestão Reagan como a Bush reduziram o número destes funcionários em apenas seis agências, enquanto que a administração Clinton a fez em 11, apresentando, portanto, uma maior capacidade de controlar a expansão de tal categoria de funcionários. Novamente, vale a pena destacar a intensa variabilidade de resultados por agência no tempo. Cada universo de reformas possui uma intensa diferenciação das capacidades de lidar com as mesmas organizações. 
Gráfico 6: Funcionários Schedule $C$ por administração

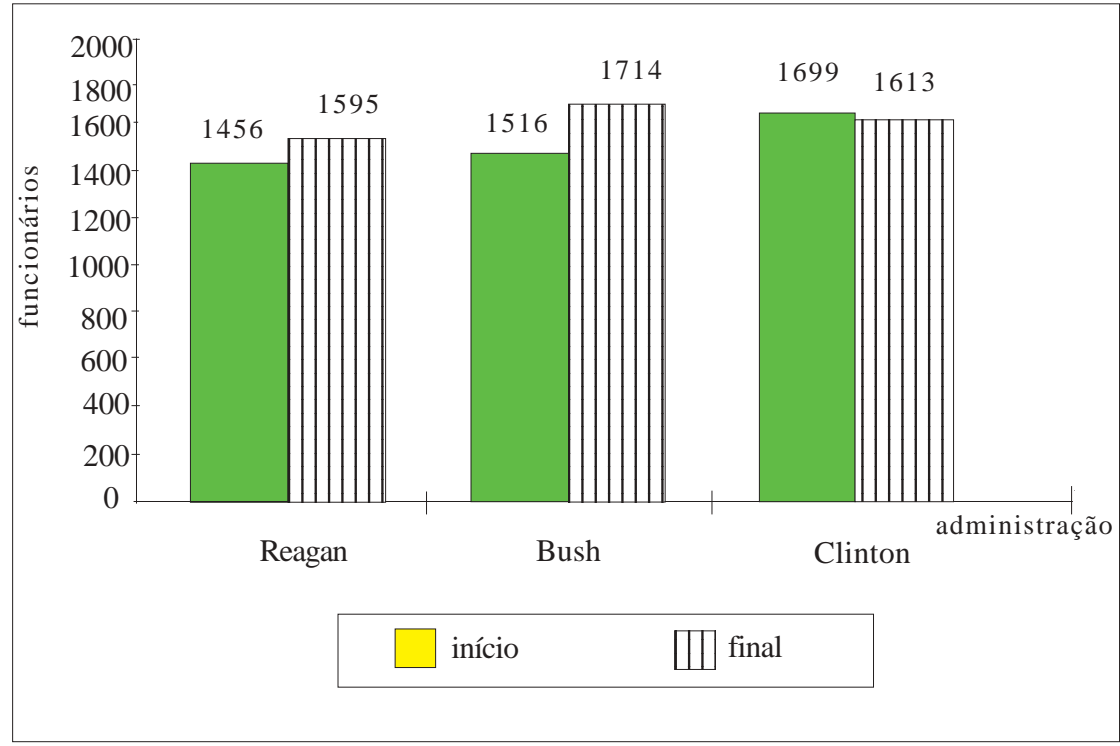

Quadro 5: Redução dos funcionários Schedule $C$ por administração e por agência

\begin{tabular}{|l|c|c|c|}
\hline Agency & $\begin{array}{c}\text { Reagan } \\
\mathbf{1 9 8 0 / 1 9 8 3}\end{array}$ & $\begin{array}{c}\text { Bush } \\
\mathbf{1 9 8 8} / \mathbf{1 9 9 1}\end{array}$ & $\begin{array}{c}\text { Clinton } \\
\mathbf{1 9 9 2 / 1 9 9 4}\end{array}$ \\
\hline Agriculture & 43 & 15 & -18 \\
\hline Commerce & -18 & 38 & 38 \\
\hline Defense & 15 & 20 & 26 \\
\hline Education & 35 & -7 & -13 \\
\hline Energy & -4 & 16 & -31 \\
\hline EPA & 8 & 16 & -1 \\
\hline General Service Administration & 17 & 9 & -10 \\
\hline HHS & -3 & 7 & -19 \\
\hline HUD & 7 & -1 & 23 \\
\hline Interior & 9 & 0 & 0 \\
\hline Justice & -9 & -5 & 33 \\
\hline Labor & -18 & 22 & 1 \\
\hline NASA & -3 & 0 & 4 \\
\hline OMB & 6 & -5 & -14 \\
\hline OPM & 15 & -3 & 8 \\
\hline State & 25 & 16 & -37 \\
\hline Transportarion & 13 & -7 & -2 \\
\hline Treasury & 5 & 43 & -15 \\
\hline Veterans Affairs & 6 & 8 & -1 \\
\hline
\end{tabular}

Fonte: OMB (1995). Budget of the United States: Historical Tables. Washington D.C. 
Em termos da efetividade de implementação das recomendações propostas pelo programa, os dados revelam que em 1996 aproximadamente 750 das 1.500 recomendações gerais foram completamente realizadas nas agências e departamentos do governo. Tais iniciativas implicaram a redução direta de 291 mil cargos públicos, possibilitando uma redução de despesas da ordem de 118 bilhões de dólares nos gastos com a administração federal.

No que se refere à desregulamentação interna das agências, dados oficiais revelam que, ao final do mesmo ano, as agências do governo reduziram cerca de 640.000 páginas de suas regulações e procedimentos internos de funcionamento. As agências regulatórias reduziram aproximadamente 16 mil páginas de suas regulações afetando o público, e reescreveram aproximadamente outras 31.000 páginas, no sentido de torná-las mais facilmente entendidas. No que diz respeito aos padrões de prestação de serviços, as agências do governo ficaram absolutamente comprometidas com o governo federal em atender aos 3.500 padrões de prestação de serviços (customer service standards), melhorando a qualidade de oferta de serviços ao consumidor. Ademais, o vice-presidente Al Gore premiou aproximadamente 800 "times de reinvenção", que trabalharam no sentido de promover as reformas no nível das agências e departamentos do governo. As agências criaram, no período, mais de 300 laboratórios de reinvenção, os quais promoveram significativos resultados, gerando um sem número de experiências bem-sucedidas.

\section{Considerações finais e pontos de interesse para as reformas em curso no Brasil}

Como considerado anteriormente, o NPR traz para a administração pública uma série de pontos inovadores que o diferencia de outras agendas americanas para as reformas do setor público. O NPR promove mais do que reformas, um novo modo de lidar com a burocracia, com as organizações e, fundamentalmente, com o modo de realizar as reformas pretendidas. O estilo descentralizado de promover transformações no modo como o governo funciona, mostra-se decisivo, para uma maior capacidade de realizar mudanças.

Outro ponto importante a ser discutido é o fato de que muito embora o NPR apregoe o combate às formas burocráticas tradicionais, e apesar de ter o setor privado e o mercado como referências para a reinvenção do governo, os formuladores do NPR não afastam a idéia de que o governo e a administração pública são necessários e condições essenciais para o funcionamento de uma economia de mercado. Este é um traço distintivo das reformas americanas. O governo tem um papel importante nas regras 
do jogo, no funcionamento da economia e da sociedade. Este princípio permite admitir que mesmo indo radicalmente de encontro aos princípios de centralização, de obediência às regras e à regulação, o NPR preserva o papel da burocracia e da administração pública, porém, sob novos princípios de funcionamento, onde a qualidade dos serviços, a preocupação com os custos e com a eficiência passam a ser para cada organização um elemento balizador das ações gerenciais.

$\mathrm{O}$ segundo ponto de interesse diz respeito às contradições trazidas pelo NPR. Se para os governos tradicionais funcionarem melhor representa custar menos, o NPR aposta que isto depende em larga medida do padrão de incentivos internos das organizações. As organizações, como mostram os dados apresentados, respondem diferentemente às intenções de reformas propostas pelo governo federal. A lógica descentralizada e de estímulo ao conhecimento e transformação gradual das estruturas de incentivos foi o modo como os formuladores driblaram as possíveis tensões políticas em torno das reformas. Os objetivos aparentemente contraditórios do programa adquirem uma lógica clara que tem a ver com a seqüência de implementação: os ganhos com a mudança dos incentivos seriam mais facilmente introduzidos na primeira fase, e as reduções de custos com o governo, a qual dependeria em muito do Legislativo e das tensões políticas que viriam no processo, seriam mais complicadas. O plano de implementação das reformas, conduzidas pelos estrategistas em Washington, revela que o duplo objetivo permitiria enfrentar nas dimensões micro (no interior das organizações e nos seus ambientes políticos específicos) e macro (no Legislativo), todas as formas de resistências políticas que poderiam minar os programas de reforma. $\mathrm{O}$ tom fragmentado à reinvenção se mostra um instrumento estratégico para lidar com as resistências políticas, e ainda o único mecanismo capaz de permitir a transformação dos incentivos sob os quais as organizações funcionam na realidade.

O NPR por ser praticamente um programa agency-based permite que os princípios e as técnicas utilizadas para a reinvenção busquem, baseadas nos diversos ambientes organizacionais, encontrar linhas de menor resistência e de maior adaptabilidade às demandas específicas de cada organização. Longe de assumir a tradicional noção de que a reinvenção deveria ser homogênea em relação às técnicas a serem utilizadas, dos resultados, ou desencadeadas a partir de um esquema único, centrado em cortes de custos, o programa buscou formas flexíveis para entender e alterar os padrões de incentivos de cada instância, propondo diferenças terapêuticas para problemas gerenciais e organizacionais diferenciados, porém realizados dentro de uma lógica geral de coordenação.

Fez-se necessário entrar numa permanente reinvenção em cada agência, procurando ver como tais organizações respondem a diferentes padrões de incentivos, ampliando simultaneamente os níveis de 
accountability e a qualidade no atendimento às demandas dos cidadãosconsumidores. Em termos gerais e de relevância para o caso brasileiro, foi a seqüência com que o NPR foi sendo implementado: em primeiro lugar, partindo de uma maior preocupação com mudanças na cultura organizacional, empowerment dos funcionários e satisfação para o cliente. Em seguida, as políticas de downsizing foram sendo introduzidas em combinação a mudanças na cultura organizacional e no padrão de incentivos das organizações do governo. Esta combinação permanente permitiu "calibrar" as demandas das reformas, sempre ajustando melhoria da performance à questão da redução dos custos.

Tal seqüência geral confere especificidade ao programa, e traz à tona a noção de que a redução do tamanho do governo se apresenta numa dimensão quase inevitável das reformas administrativas, e que o caso americano não se constitui exceção. No entanto, mesmo na experiência americana, e que serve como ponto de reflexão para o caso brasileiro, algumas questões relativas aonde cortar o governo, por onde começar, e quais os riscos e impactos envolvidos nestas políticas são issues revisitadas nestas iniciativas. No caso do NPR, tais questões foram problemáticas, e não tem sido fácil implementar os pretendidos objetivos de downsizing. Assume relevância a habilidade política para lidar com as poderosas coalizões congressionais no sentido de obter cooperação. A experiência do caso do NPR aponta para um forte embate entre o tecnicamente planejado e o politicamente realizado. Diante de conflitos, a dimensão do politicamente realizável parece ser uma agenda plausível de encaminhamento das reformas. $\mathrm{O}$ avanço das reformas sobre dois importantes fronts permite, em grande medida, manobras para encontrar no momento adequado as linhas de menor resistência, ganhando tempo na implementação das reformas. Habilidosos formuladores de reformas não deveriam esquecer a dimensão política delas, o que exige bastante flexibilidade tanto no plano técnico de implementação como no de formulação das mesmas.

Por outro lado, a engenharia institucional do NPR, tal como a questão das mudanças na cultura organizacional e das estruturas de incentivos das organizações do governo, embora não enfrentando da mesma maneira as resistências reais do Congresso, e dependendo mais do grau de envolvimento individual de cada agência com os objetivos gerais do programa de reformas, serve como referência e reflexão para o caso brasileiro. A busca do conhecimento acerca dos padrões de funcionamento, dos padrões gerenciais e das estruturas de incentivos, como perseguido pelo NPR, mostra que o conhecimento institucional das realidades das diversas organizações que compõem o governo constitui um fator de sucesso para as reformas administrativas. Outro ponto a ser destacado aqui é o fato de que a permanente preocupação de "entrar na realidade das organizações", entender os padrões internos de funcionamento das 
organizações, ajustar as reformas ao dia-a-dia das organizações, tem em muito a ver com o espírito das reformas do NPR, e serve como ponto de reflexão para as reformas no Brasil. Se o NPR traz para o Brasil um ensinamento, este é o de entender melhor as organizações, encontrar os mecanismos adequados para as reformas antes de entrar em combate com os problemas burocráticos crônicos. Primeiro, entender; segundo, remediar; e terceiro, ter habilidade política para eliminar excessos. 
Lista de anexos

Anexo 1: Breve cronologia dos programas federais de reformas no Executivo americano (1905-1993)

Anexo 2: NPR - Reinvenção do governo: iniciativas, objetivos, mudanças e ações realizadas em 1996

Anexo 3: Sistemas de gestão de pessoal

Anexo 4: Sistemas de contratação de pessoal

Box 1: O sistema americano de melhoria da performance individual e das organizações do governo

Box 2: Mecanismos institucionais para o controle do gasto e déficit público no governo americano (1974-1993) 
Anexo 1: Breve cronologia dos programas federais de reformas no Executivo americano (1905-1993)

\begin{tabular}{|c|c|c|c|c|}
\hline $\begin{array}{l}\text { Data de im- } \\
\text { plementação } \\
\text { do programa }\end{array}$ & Presidente & Partido & $\begin{array}{l}\text { Programa de } \\
\text { reforma } \\
\text { administrativa }\end{array}$ & $\begin{array}{l}\text { Missão e objetivo } \\
\text { programático }\end{array}$ \\
\hline 1905-1909 & $\begin{array}{l}\text { Theodore } \\
\text { Roosevelt }\end{array}$ & Republicano & $\begin{array}{l}\text { Keep } \\
\text { Commission }\end{array}$ & $\begin{array}{l}\text { Gestão de pessoal e } \\
\text { sistemas de informação }\end{array}$ \\
\hline 1910-1913 & $\begin{array}{l}\text { William } \\
\text { Taft }\end{array}$ & Republicano & $\begin{array}{l}\text { President's } \\
\text { Commission on } \\
\text { Economy and } \\
\text { Efficiency }\end{array}$ & $\begin{array}{l}\text { Definição do } \\
\text { Orçamento das } \\
\text { Agências do Executivo }\end{array}$ \\
\hline 1921-1924 & $\begin{array}{l}\text { Warren } \\
\text { Handing }\end{array}$ & Republicano & $\begin{array}{l}\text { Joint } \\
\text { Commission on } \\
\text { Reorganization }\end{array}$ & $\begin{array}{l}\text { Redistribuição de } \\
\text { funções executivas } \\
\text { entre departamentos }\end{array}$ \\
\hline 1936-1937 & $\begin{array}{l}\text { Franklin } \\
\text { Roosevelt }\end{array}$ & Democrata & $\begin{array}{l}\text { President's } \\
\text { Commision on } \\
\text { Administrative } \\
\text { Management }\end{array}$ & $\begin{array}{l}\text { Gestão de Pessoal, } \\
\text { formas de contratação } \\
\text { de serviços, e Gestão } \\
\text { de Informação }\end{array}$ \\
\hline 1947-1949 & $\begin{array}{l}\text { Henry } \\
\text { Truman }\end{array}$ & Democrata & $\begin{array}{l}\text { First Hoover } \\
\text { Commission }\end{array}$ & Orçamento Nacional \\
\hline 1953-1955 & $\begin{array}{l}\text { Dwight } \\
\text { Eisenhower }\end{array}$ & Republicano & $\begin{array}{l}\text { Second Hoover } \\
\text { Commission }\end{array}$ & $\begin{array}{l}\text { Redistribuição de } \\
\text { Funções no Executivo. }\end{array}$ \\
\hline 1953-1968 & $\begin{array}{l}\text { Dwinght } \\
\text { Eisenhower }\end{array}$ & Republicano & $\begin{array}{l}\text { Study } \\
\text { Commission on } \\
\text { Executive } \\
\text { Reorganization }\end{array}$ & $\begin{array}{l}\text { Reorganização do } \\
\text { Sistema } \\
\text { Administrativo }\end{array}$ \\
\hline 1968-1971 & $\begin{array}{l}\text { Richard } \\
\text { Nixon }\end{array}$ & Republicano & Ash Council & $\begin{array}{l}\text { Reestruturação do } \\
\text { Executivo }\end{array}$ \\
\hline 1977-1079 & $\begin{array}{l}\text { James } \\
\text { Carter }\end{array}$ & Democrata & $\begin{array}{l}\text { Carter } \\
\text { Reorganization } \\
\text { Effort }\end{array}$ & $\begin{array}{l}\text { Reorganização dos } \\
\text { processos internos do } \\
\text { governo }\end{array}$ \\
\hline 1982-1984 & $\begin{array}{l}\text { Ronald } \\
\text { Reagan }\end{array}$ & Republicano & $\begin{array}{l}\text { Grace } \\
\text { Commission }\end{array}$ & $\begin{array}{l}\text { Controle de Custos } \\
\text { com o Governo }\end{array}$ \\
\hline 1993 - & $\begin{array}{l}\text { Willian } \\
\text { Clinton }\end{array}$ & Democrata & $\begin{array}{l}\text { National } \\
\text { Performance } \\
\text { Review }\end{array}$ & $\begin{array}{l}\text { Reinventar Governo: } \\
\text { funcionar melhor e } \\
\text { custar menos. }\end{array}$ \\
\hline
\end{tabular}

Adaptação de Di Iulio, Kettl and Garvey (1993). Improving Governmental Performance: an owner's manual. Washington D.C. Brookings Institution. 
Anexo 2: NPR - Reinvenção do governo: iniciativas, objetivos, mudanças e ações realizadas em 1996

\begin{tabular}{|c|c|c|c|}
\hline Principais iniciativas & Objetivo Geral & Natureza da mudança & Ação realizada (1996) \\
\hline $\begin{array}{l}\text { Organizações } \\
\text { voltadas para a } \\
\text { performance }\end{array}$ & $\begin{array}{l}\text { Aumentar níveis de } \\
\text { accountability } \\
\text { Orientação por resul- } \\
\text { tados e qualidade }\end{array}$ & $\begin{array}{l}\text { Alterar estrutura } \\
\text { interna de incenti- } \\
\text { vos nas agências } \\
\text { do governo. }\end{array}$ & $\begin{array}{l}\text { Criação de } \\
\text { Performance Based } \\
\text { Organizations (PBO) }\end{array}$ \\
\hline $\begin{array}{l}\text { Definição dos } \\
\text { serviços prestados } \\
\text { por cada agência }\end{array}$ & $\begin{array}{l}\text { Melhorar relação } \\
\text { entre as agências do } \\
\text { governo e clientela }\end{array}$ & $\begin{array}{l}\text { Definir serviços a } \\
\text { serem prestados } \\
\text { por cada agência e } \\
\text { departamento }\end{array}$ & $\begin{array}{l}\text { Desenvolver em } \\
\text { cada agência pa- } \\
\text { drões de prestação } \\
\text { de serviços } \\
\text { (customer service) }\end{array}$ \\
\hline $\begin{array}{l}\text { Parcerias } \\
\text { regulatórias }\end{array}$ & $\begin{array}{l}\text { Reduzir ineficiências } \\
\text { decorrentes da ação } \\
\text { regulatória do governo } \\
\text {. Melhorar a capaci- } \\
\text { dade de enforcement } \\
\text { do governo. }\end{array}$ & $\begin{array}{l}\text { Alterar padrões de } \\
\text { regulação pública, } \\
\text { alterando incentivos } \\
\text { e estruturas de re- } \\
\text { gulação de agências } \\
\text { e entre agências. }\end{array}$ & $\begin{array}{l}\text { Estimular o uso de } \\
\text { iniciativas envol- } \\
\text { vendo regulação } \\
\text { conjunta entre } \\
\text { agências, e evitar } \\
\text { as relações adver- } \\
\text { sariais entre o setor } \\
\text { público e privado. }\end{array}$ \\
\hline \multirow[t]{2}{*}{$\begin{array}{l}\text { Performance- } \\
\text { based partnership } \\
\text { grants }\end{array}$} & $\begin{array}{l}\text { Estimular o desen- } \\
\text { volvimento de par- } \\
\text { cerias entre três } \\
\text { níveis de governo } \\
\text { em áreas de políticas } \\
\text { públicas de respon- } \\
\text { sabilidade de mais } \\
\text { uma esfera de gover- } \\
\text { no, evitando super- } \\
\text { posição de compe- } \\
\text { tências. }\end{array}$ & $\begin{array}{l}\text { Melhorar as rela- } \\
\text { ções entre as esfe- } \\
\text { ras de governo } \\
\text { visando melhores } \\
\text { resultados, e am- } \\
\text { pliando o uso qua- } \\
\text { litativo de recursos } \\
\text { federais. }\end{array}$ & $\begin{array}{l}\text { Associar dotações } \\
\text { federais a formação } \\
\text { de parcerias e } \\
\text { performance; for- } \\
\text { mação de parcerias } \\
\text { entre agências locais } \\
\text { e federais. }\end{array}$ \\
\hline & $\begin{array}{l}\text { Reformar padrões } \\
\text { de incentivos nas } \\
\text { relações entre fun- } \\
\text { cionários públicos e } \\
\text { agências do governo, } \\
\text { visando orientação } \\
\text { por resultados, } \\
\text { performance e qua } \\
\text { lidade dos serviços } \\
\text { prestados ao consu- } \\
\text { midor final. }\end{array}$ & $\begin{array}{l}\text { Alterar padrões de } \\
\text { regulação nas rela- } \\
\text { ções entre funcio- } \\
\text { nário público e o } \\
\text { serviço em áreas } \\
\text { como: acesso ao } \\
\text { cargo, salários, e } \\
\text { gestão interna de } \\
\text { pessoal. }\end{array}$ & $\begin{array}{l}\text { Investir na força de } \\
\text { trabalho; } \\
\text { Alterar regulações } \\
\text { ajustando incenti- } \\
\text { vos às especificida- } \\
\text { des de cada agência } \\
\text { e ao padrão de } \\
\text { serviços a serem } \\
\text { prestados. }\end{array}$ \\
\hline
\end{tabular}

Fonte: Relatório do NPR. 
Anexo 3: Sistemas de gestão de pessoal

\begin{tabular}{|c|c|c|c|}
\hline $\begin{array}{l}\text { Principais } \\
\text { problemas }\end{array}$ & Evidências & $\begin{array}{l}\text { Necessidade de } \\
\text { mudança }\end{array}$ & $\begin{array}{l}\text { Recomendações } \\
\text { gerais do NPR }\end{array}$ \\
\hline $\begin{array}{l}\text { Centralização e } \\
\text { reduzida capa- } \\
\text { cidade do siste- } \\
\text { ma em promover } \\
\text { eficiência e } \\
\text { accountability. }\end{array}$ & $\begin{array}{l}\text { Performance tem } \\
\text { reduzida conexão } \\
\text { com objetivos e } \\
\text { missão das orga- } \\
\text { nizações. }\end{array}$ & $\begin{array}{l}\text { Redefinir o } \\
\text { significado da } \\
\text { accountability. } \\
\text {. Associar } \\
\text { accountability ao } \\
\text { mérito, a missão e } \\
\text { ao senso de orienta- } \\
\text { ção pela eqüidade e } \\
\text { igualdade de opor- } \\
\text { tunidades. }\end{array}$ & $\begin{array}{l}\text { Criação de sistemas } \\
\text { descentralizados de } \\
\text { gestão de pessoal } \\
\text { voltados para auto- } \\
\text { nomia, accountability } \\
\text { e performance. }\end{array}$ \\
\hline $\begin{array}{l}\text { Agências têm } \\
\text { reduzido poder } \\
\text { decisório sobre } \\
\text { padrões de ges- } \\
\text { tão dos seus } \\
\text { funcionários. }\end{array}$ & $\begin{array}{l}\text { Gerentes têm redu- } \\
\text { zida capacidade de } \\
\text { aproveitar as melho- } \\
\text { res capacidades dos } \\
\text { funcionários. }\end{array}$ & $\begin{array}{l}\text {. Agências devem ter } \\
\text { seus próprios siste- } \\
\text { mas de gestão de } \\
\text { pessoal, adaptado } \\
\text { às especificidades } \\
\text { de seus objetivos e } \\
\text { cultura organizacio- } \\
\text { nal. }\end{array}$ & $\begin{array}{l}\text { Reformulação do } \\
\text { sistema de classi- } \\
\text { ficação de pessoal. }\end{array}$ \\
\hline \multirow[t]{2}{*}{$\begin{array}{l}\text { Inflexibilidade } \\
\text { nos critérios de } \\
\text { classificação e de } \\
\text { remuneração. }\end{array}$} & \multirow[t]{2}{*}{$\begin{array}{l}\text { Accountability redu- } \\
\text { zida ao atendimento } \\
\text { a procedimentos, } \\
\text { comandos e normas, } \\
\text { pouco tendo a ver } \\
\text { com a performance } \\
\text { individual dos fun- } \\
\text { cionários. }\end{array}$} & $\begin{array}{l}\text { Aumentar poder e } \\
\text { responsabilidade } \\
\text { dos executivos e } \\
\text { gerentes federais no } \\
\text { design e elaboração } \\
\text { dos sistemas de } \\
\text { gestão de pessoal. }\end{array}$ & $\begin{array}{l}\text { Estímulo a progra- } \\
\text { mas de melhoria do } \\
\text { ambiente e das rela- } \\
\text { ções de trabalho no } \\
\text { interior das agências. }\end{array}$ \\
\hline & & $\begin{array}{l}\text { Qualidade e efetivi- } \\
\text { dade do sistema de } \\
\text { gestão de pessoal } \\
\text { deve ser mensurado } \\
\text { em termos do que } \\
\text { este produz em } \\
\text { termos da missão, } \\
\text { objetivos e priori- } \\
\text { dades das agências. }\end{array}$ & $\begin{array}{l}\text { Orientação pelos } \\
\text { princípios de igual- } \\
\text { dade de oportuni- } \\
\text { dades no atingimento } \\
\text { de resultados e } \\
\text { performance } \\
\text { individual. } \\
\text { Formação de parce- } \\
\text { rias entre gerentes e } \\
\text { trabalhadores no } \\
\text { design dos sistemas } \\
\text { de incentivos. }\end{array}$ \\
\hline
\end{tabular}

Fonte: Relatório do NPR. 


\begin{tabular}{|c|c|c|}
\hline Problemas & Evidências e impactos & Necessidade de mudança \\
\hline $\begin{array}{l}\text { Centralização das } \\
\text { decisões no Office of } \\
\text { Personnel and } \\
\text { Management (OPM). } \\
\text {. Reduzida capacidade } \\
\text { para atender às necessi- } \\
\text { dades dos seus usuá rios. } \\
\text { Pouco estímulo a compe- } \\
\text { titividade na seleção e } \\
\text { avaliação de candidatos. }\end{array}$ & $\begin{array}{l}\text { Reduzido envolvimento } \\
\text { dos gerentes no recruta- } \\
\text { mento, seleção e avalia- } \\
\text { ção dos candidatos. } \\
\text { Aplicantes são deses- } \\
\text { timulados. } \\
\text { O sistema estimula lon- } \\
\text { longo tempo para efe- } \\
\text { tivar a contratação de } \\
\text { pessoal; } \\
\text {. Complexidade do sis- } \\
\text { tema gera a necessi- } \\
\text { dade de pessoal alta- } \\
\text { mente especializado } \\
\text { para interpretação e } \\
\text { aplicação das normas. } \\
\text { Ênfase no princípio da } \\
\text { eqüidade interna reduz } \\
\text { capacidade do governo } \\
\text { em competir por recur- } \\
\text { sos humanos adequa- } \\
\text { dos no mercado. } \\
\text { Reduzidos incentivos } \\
\text { para inovação. }\end{array}$ & $\begin{array}{l}\text {. Autorizar as agências } \\
\text { para estabelecer seus } \\
\text { próprios mecanismos de } \\
\text { recrutamento de pessoal. } \\
\text {. Permitir que os departa- } \\
\text { mentos e agências deter- } \\
\text { minem suas próprias } \\
\text { necessidades de recru- } \\
\text { tamento de pessoal. } \\
\text {. Permitir que os departa- } \\
\text { mentos e agências sejam } \\
\text { responsáveis diretamen- } \\
\text { te pela contratação de } \\
\text { pessoal. } \\
\text {. Permitir que os funcio- } \\
\text { nários em regime tempo- } \\
\text { rário busquem competir } \\
\text { por regime de perma- } \\
\text { nência no trabalho, de } \\
\text { acordo com procedi } \\
\text { mentos determinados } \\
\text { internamente. } \\
\text {. Criar uma estrutura geral } \\
\text { de qualificação permitin- } \\
\text { do que as agências e } \\
\text { departamento progressi- } \\
\text { vamente alterem seus } \\
\text { padrões. } \\
\text {. Eliminar as regras esta- } \\
\text { tutárias acerca de posi- } \\
\text { ções de regime temporá- } \\
\text { rio de trabalho. } \\
\text { federal. } \\
\text { gromover um sistema de informações } \\
\text { sobre oportunidades de }\end{array}$ \\
\hline
\end{tabular}

Fonte: NPR — Vários relatórios (elaboração do autor) 


\section{Box 1: O sistema americano da melhoria da performance individual e das organizações do governo}

Nos Estados Unidos, o setor público e suas organizações desde o Civil Service Reform Act de 1978 funcionam de modo orientado pela performance e desempenho individual. Para tal, o governo federal estabeleceu a criação de sistemas de gestão da performance para os funcionários federais, os quais associam o salário à performance individual no trabalho. Tal sistema foi montado de modo a funcionar como um veículo para a melhoria da performance individual mediante a melhoria das comunicações relativas à performance esperada dos funcionários e supervisores. Um plano de trabalho anual, contendo os elementos críticos e os padrões de performance, tem sido o elemento orientador do planejamento individual das agências e do acompanhamento dos trabalhos. Um sistema de permanente feedback, vindo de cada supervisor, alimenta as informações para a produção de um sistema de feedback para os funcionários, e ainda para a produção de informações de um relatório final anual. As decisões gerenciais nas promoções, premiações, treinamento e retenção estão ligadas diretamente ao processo de gestão da performance. Atualmente, existem sistemas separados de gestão da performance para supervisores e para gerentes gerais (general managers), os quais são incluídos no Performance Management and Recognition System (PMRS). Os funcionários são incluídos no General Schedule.

Em maio de 1993, o Office of Personnel Management produziu um relatório de trabalho, o Principles and Features of Performance Management Reform, visando mudanças nos sistemas de performance, cujas recomendações eram em alguma medida bastantes similares àquelas geradas pelo programa National Performance Review. O diagnóstico de tal relatório era de que os sistemas existentes de performance, na perspectiva de instituições como o General Accounting Office, Merit Sistem Protection Board, National Academy of Public Administration, National Research Council, e outros, haviam progressivamente perdido suas capacidades de melhorar a performance individual e das organizações. Os fatores principais que haviam produzido tal condição eram de diversas naturezas, os quais poderiam ser listados da seguinte forma:

1) Os sistemas de gestão da performance haviam sido dimensionados para atender múltiplos, e por muitas vezes, propósitos conflitantes.

2) Os sistemas operam para o governo como um todo, são bastante inflexíveis, e não suficientemente adequados para atender às necessidades variáveis das diversas culturas organizacionais das agências federais.

3) Os sistemas não são internalizados pelos gerentes que têm de fazer com que estes funcionem, mas, sim pelo Office of Personnel Management. 
4) Ênfase exagerada em lidar com aqueles que têm performance considerada baixa, e ao mesmo tempo, insuficiente ênfase na melhoria da performance da maioria dos empregados que têm expectativas sobre aquilo que eles podem fazer melhor no futuro.

5) Os sistemas são percebidos como sistemas de controle topdown, ao invés de serem instrumentos para dotar os funcionários de poder, e ainda os supervisores para melhoria da performance.

6) Ênfase na performance individual, e pouco suporte aos esforços emergentes para o gerenciamento de grupos e performance organizacional.

7) Os funcionários federais sempre se reportam aos sistemas como tendo comunicação inadequada das expectativas da performance, e ainda sobre o feedback do sistema para os funcionários.

8) Existem problemas na classificação das performances, nas quotas, e percepções negativas acerca de um sistema satisfatório que permita a classificação pela performance.

9) Os relatórios de performance representam sempre uma ameaça ao funcionário e ao supervisor, inibindo as oportunidades de comunicação efetiva entre eles.

10) Os escores de performance são geralmente pensados para serem inflacionados, não revelando os verdadeiros esforços individuais, e ainda não são igualmente distribuídos de acordo com critérios como formação profissional, sexo, ocupação, locação geográfica, e por agência.

De modo a lidar com tais pontos críticos, o NPR considera como sistema ideal de gestão da performance aquele que funciona centrado num único objetivo: a melhoria da performance individual e organizacional. As agências do governo devem ser estimuladas a desenvolver programas de gestão de performance, dimensionados para atender suas necessidades individuais e em sintonia com suas culturas organizacionais. Tais programas procurarão melhorar a performance de todos os funcionários, e não apenas aqueles que atingem padrões esperados de performance. Os funcionários e seus representantes serão envolvidos na concepção e implementação de programas de gestão da performance. Os sistemas internos de feedback, durante e no final do período, devem ser orientados pelo princípio de como melhorar a performance futura. Para reforçar a ênfase em tal princípio, os sistemas de rating da performance, assim como as premiações, devem ser disassociados e independentes. As decisões relativas ao reconhecimento devem incluir fatores específicos para o trabalho de grupo, missão e cultura das organizações.

O NPR assume como necessárias as seguintes ações:

a) autorizar as agências a elaborarem os seus próprios programas de gestão da performance (to design);

b) implementar programas de gestão da performance baseado nos seguintes princípios: 
- melhoria da performance individual e organizacional;

— os funcionários e/ou seus representantes devem estar envolvidos na concepção e implementação dos programas, bem como no desenvolvimento da performance esperada, e receber feedback pela melhoria da performance futura;

— no mínimo, dois níveis de performance devem ser identificados: atingir ou não as expectativas;

— descentralização da gestão da performance dentro de uma estrutura de princípios gerais para todo o governo porém, atendendo às necessidades individuais de cada agência;

c) as agências devem ser capazes de desenvolver seus programas individuais de gestão da performance voltados para todos os funcionários, e essencialmente gerenciados e controlados pelos gerentes das agências.

\section{Box 2: Mecanismos institucionais para o controle do gasto e déficit público no governo americano (1974-1993)}

O ano de 1974 introduz uma profunda mudança no sistema político-institucional americano no que se refere às relações de poder nas decisões sobre o processo orçamentário, visando eficiência e racionalidade no uso de recursos públicos, e por conseqüência, um maior compromisso do Legislativo e do Executivo nesta questão. Neste sentido, o Congresso aprovou o Budget Impoundment Act, o qual introduz dispositivos permitindo uma maior racionalidade e controle do Legislativo sobre o processo e as questões orçamentárias, alterando as relações históricas entre o Presidente e o Congresso na definição do Orçamento Nacional. Com as inovações trazidas pelo Budget Impoundment Act, as decisões congressionais relativas ao orçamento foram altamente descentralizadas para os comitês e subcomitês na House of Representatives e no Senado, ao mesmo tempo que ampliou a difusão da informação sobre o orçamento entre os membros do Congresso. A partir de então, verifica-se, no Congresso, um maior controle sobre as propostas orçamentárias do Presidente. O Budget Impoundment Act regulou as decisões no processo orçamentário até 1984, quando o presidente Reagan introduziu novas e mais mudanças institucionais radicais com a formulação de um novo mecanismo, especialmente elaborado para lidar com a redução dos gastos públicos em 1985. O Congresso americano aprovou, em 1985, o Gramm-Rudman-Hollings Act, conhecido como o Balanced Budget and Emergency Deficit Control Act, o qual ampliou a participação do Legislativo introduzindo um dispositivo automático dos cortes nos gastos públicos, caso os históricos conflitos entre Presidência e Legislativo se tornassem muito longos na definição do orçamento nacional, sobretudo no que se refere aos cortes dos gastos nas agências do governo. Com as novas regras do jogo, o presidente e o 
diretor do Office of Management and Budget (OMB), juntamente com líderes do Congresso, ficaram responsáveis por encontrar acordos sobre pontos conflituais na definição das prioridades do orçamento, sobretudo no que se refere ao nível de gasto e controle do déficit. A principal inovação institucional do Gramm-Rudman está no controle do déficit público, onde o orçamento nacional passou a ser definido de modo a que os déficits anuais sejam progressivamente reduzidos até o ponto em que o déficit público seja zerado e equilibrado o orçamento. O Gramm-Rudman tornou claro para os atores institucionais, que, em caso de insucesso na redução do déficit público num dado ano fiscal, um corte generalizado em todas as agências (este processo é chamado de sequestration) seria realizado indiscriminadamente pelo Legislativo, através do General Accounting Office (GAO), em todas as agências do Executivo. Em 1986, dado o intenso poder dado ao GAO neste novo mecanismo institucional, a Supreme Court declarou o ato de 1985 inconstitucional, alegando que a responsabilidade no processo de seqüestro de recursos deveria ser exercida por uma agência do poder Executivo e não pelo Legislativo. As revisões do Gramm-Rudman, no sentido de torná-lo constitucional, foram atendidas em 1986, e permanecem até hoje. Nesta nova versão, o Gramm-Rudman transfere o poder de sequiestro do GAO (Legislativo) para o OMB (Executivo), situado no Executive Office of the President (EOP), expandindo consideravelmente o poder do presidente sobre a definição dos gastos e do controle do déficit. O OMB passou a ser o ator principal no processo, tendo os seguintes papéis: estimar os cortes nos gastos do governo; definir quais programas devem ser poupados do seqüestro de recursos; definir as prioridades dos gastos e outras questões relativas ao orçamento. As provisões congressionais introduzidas nos anos 90 mantêm o poder do OMB como principal ator institucional no processo do equilíbrio orçamentário.

Fonte:Adaptação de Lowi, Theodore e Benjamin Ginsberg (1990). 
1 Este trabalho foi especialmente realizado no contexto da pesquisa sobre Experiências Internacionais de Reformas Administrativas na Escola Nacional de Administração Pública - ENAP/BR. Sou devidamente grato à orientação recebida do prof. Theodore Lowi na Cornell University durante a fase de preparação do material necessário à pesquisa bibliográfica, e sobre a condução do estudo, durante o estudo independente em políticas públicas sob sua supervisão no fall de 1997. Ainda sou grato aos comentários e sugestões da Diretoria de Difusão e Pesquisa — DPD, os quais foram indispensáveis para que o trabalho assumisse esta forma final.

2 A fonte primária do trabalho corresponde aos relatórios oficiais gerados pelo National Performance Review ao longo de suas fases. As fontes secundárias aqui utilizadas são várias: para as séries históricas de dados apresentados nos gráficos ao longo do texto, quando não especificadas as fontes, são os documentos oficiais do Office of Management and Budget (OMB), General Accounting Office (GAO), livros, artigos de jornais, documentos congressionais e ainda artigos publicados sobre o tema nas principais revistas especializadas sobre políticas públicas e administração pública nos Estados Unidos.

3 Diversas análises e estudos realizados sobre o NPR consideram que uma avaliação precisa dos resultados dos NPR, dado sua natureza extremamente fragmentada, tratase de tarefa de difícil mensuração objetiva, sobretudo no que se refere à parte mais qualitativa do programa de reformas. Seguindo tal recomendação analítica, este trabalho apresenta um reduzido painel quantitativo com resultados alcançados pelo programa, servindo apenas para inferir de modo geral de como os objetivos programáticos do NPR foram processados de modo diferente nos diversos setores do governo, bem como cada um destes setores respondem de modo diferenciado ao programa de reformas, e não como elementos que permitem avaliar normativamente o programa, objetivo que transcende em muito aos propósitos deste trabalho.

4 No anexo 1 é apresentado uma síntese da cronologia das reformas administrativas nos EUA, considerando os seus objetivos e missão programática.

5 A expressão reinventar o governo se constituiu na base do discurso das reformas Clinton. Tal expressão é claramente tomada emprestada do livro Reinventing the Government: How the Entrepreneurial Spirit is transforming the Public Sector, escrito por David Osborne e Ted Gabler em 1992. Neste período, o presidente Clinton estava em campanha presidencial, e foi de pronto atraído pela idéia da reinvenção, a qual já vinha sendo há muito aplicada em diversos governos locais dos EUA com considerável sucesso. A influência de tais idéias na formulação do programa pode ser melhor entendida quando David Osborne integrou a equipe de consultores durante a elaboração do primeiro relatório do NPR em 1993.

6 A expressão work better and cost less aparece no discurso oficial do programa e é o motivo central do programa de reinvenção, em todas as suas fases. Na expressão, estão presentes os objetivos principais (as forças motrizes) desta política pública, e que em si encerram uma forte tensão dado o grau de conflito entre funcionar melhor e custar menos, como será explorado adiante.

7 No original "The goal of the NPR is to provide the American People with a more effective, efficient and responsive government - a government that works better and costs less. The NPR began in March 3, 1993, when I asked Vice President Al Gore to conduct an intensive 6 months review of how the Federal Government works. The Vice 
President organized a team of Federal employees from all the corners of government to examine both agencies and cross-cutting systems, such as budgeting, financial management, procurement, and personnel". Cf. Congressional Record, p. S14380 Report of Proposed Legislation entitled "Government Reform and Savings Act of 1993: Message from the President", MP 62. (House and Senate, October 26, 1993).

8 Após a elaboração do primeiro relatório, a equipe técnica ficou responsável pela implementação de diversas iniciativas nas agências do governo, tais como: treinamento de funcionários federais sobre serviços de atendimento ao consumidor-cidadão; criação dos laboratórios de reinvenção; reorganização das funções nas estruturas organizacionais e administrativas, e ainda apoiando na criação dos Conselhos InterAgências, tais como o National Partnership Council, the President Management, e.g.

9 No Box 2 em anexo são apresentadas as principais especificidades dos mecanismos institucionais utilizados pelo governo americano desde os anos 70 para controle do déficit e do gasto público. De acordo com os mecanismos institucionais disponíveis desde 1985, o OMB passou a ter um elevado papel no controle e na definição da agenda alocativa do governo, sobretudo no seu poder constitucional de exercer o sequestration como mecanismo automático de redução do déficit público nos EUA a partir do governo Reagan.

${ }^{10}$ Um dos fundamentos teóricos que apóiam a idéia de que as organizações do governo, em alguma medida, podem funcionar a partir de mecanismos de mercados é a principal-agency theory, no campo da economia institucional e teoria das organizações, e ainda na economia do trabalho. Nesta perspectiva téorica, os argumentos vão na direção da correlação positiva entre introdução de incentivos de mercados nos contrato e ganhos de eficiência. Neste sentido, os incentivos contratuais fazem a diferença nas relações entre entre a ação individual e organizacional, sobretudo no que se refere a problemas de compliance. A literatura aponta alguns conhecidos sistemas de incentivos nos contratos: pay for performance, contratos lineares, não lineares, e.g. Uma essencial revisão da literatura recente ver GibBons, Robert (1996). Incentives and Careers in Organizations. National Bureau of Economic Research, ou. ainda, Gibbons, Robert (1996). Game Theory and Garbage Cans. Ithaca. Cornell University. mimeo.

${ }^{11} \mathrm{Um}$ amplo panorama das principais correntes teóricas da economia das organizações e instituições, ver Foss, Pal (ed) (1995)., Economic Approaches to Organizations and Institutions: an Introduction. Brookfield. Dartmouth.

12 No Anexo 2, apresentado no final do texto, pode ser visualizado uma panorâmica exposição sumária das iniciativas, objetivos, natureza da mudança e ações implementadas no ano de 1996. Para maiores detalhes sobre tais iniciativas específicas cf. http://www.npr.gov, ou ainda consultar os relatórios de acompanhamento do programa.

13 Em anexo é apresentado o Box 1 - O Sistema americano de melhoria da performance organizacional e individual, o qual traça em breves linhas uma história do modelo americano de gerenciamento de performance na organização pública desde o Civil Service Reform Act de 1978, suas falhas, e ainda as principais propostas gerais de transformação sugeridas pelos formuladores do NPR.

14 Um amplo panorama das reformas administrativas no setor público em diversos governos locais e centrais europeus pode ser encontrada em NASCHOLD, Frieder (ed) (1996). New frontiers in public sector management: trends and issues in state and local government in Europe. New York: Walter de Gruyter. Em breves linhas, as reformas do setor público na Nova Zelândia e Inglaterra apresentam pontos comuns em termos dos princípios, porém diferem em alguma medida nas técnicas utilizadas pelos reformistas. No primeiro caso, pode-se observar um radical movimento na direção da reengenharia no setor público através da introdução de mecanismos de 
mercado para o funcionamento das agências do governo. No caso inglês, a orientação das reformas seguiu o caminho mais próximo da privatização radical, de mecanismos de mercado e de modernização interna das agências do governo.

15 No que se refere aos padrões de prestação dos serviços, vale salientar, por exemplo, que em 1994, uma das maiores iniciativas do programa foi a de ajudar as agências a definir os seus padrões de prestação de serviços (customer service standards). Em números, os dados oficiais revelam que um ano depois do primeiro relatório do NPR, aproximadamente 150 agências do governo haviam definido com precisão mais de 1.500 padrões de serviços a serem prestados. No ano seguinte, 214 agências do governo haviam produzido cerca de 3.000 padrões de serviços. Tal detalhamento dos serviços a serem prestados aos consumidores possibilita, em grande medida, definir claramente o que cada componente do setor público será responsável perante sua clientela e com qual padrão, gerando, assim, maior possibilidade de ampliar os níveis de accountability.

16 A idéia de downsizing, i.e., reduzir o tamanho do governo, continuaria de modo mais forte assumindo a posição central das preferências do formuladores doNPR durante sua segunda fase de implementação em 1995. Naquele momento, os resultados pretendidos pela primeira fase da reinvenção não haviam sido de longe conseguidos, e ainda haviam grandes imprecisões no que se refere às mudanças nas preferências políticas do Congresso, o qual exerceria uma nova demanda por reformas, especialmente caso este se constituísse de uma maioria republicana conservadora em termos de governo e gastos públicos. Para uma compreensão deste momento específico, ver o relatório produzido por Kettl, Donald and John Di Iulio Jr (1995). Cutting Government. Washington D.C. Brookings Institution.

17 Os Anexos 3 e 4 mostram de forma breve e esquemática os problemas, os pontos críticos nos sistemas de gestão e contratação de pessoal nos EUA, bem como a natureza das mudanças propostas com as reformas do NPR.

18 De acordo do OMB, o número de funcionários federais (Full-Time Equivalent FTE) em 1993 era de 2.139.000. O número total de funcionários federais, incluindo outras categorias e political appointees atingia a marca de 2.157.000 funcionários, sendo que $42 \%$ destes pertenciam no Departamento de Defesa. Cf. OMB (1997). Budget of the United States Government: Historical Tables. Washington D.C

19 O corte de pessoal, de acordo com fontes oficiais, foi um dos pontos que demandou intenso esforço dos decisores em Washington, dado o grau de risco e incerteza quanto os impactos de tais iniciativas sobre o funcionamento da administração pública, bem como pelo custo político de tais medidas. O elevado grau de incerteza em relação aos cortes se daria na medida em que os formuladores do programa não tinham uma sólida base empírica para efetuar tais cortes de pessoal. O Relatório Horn, elaborado pela maioria republicana pelo subcomitê responsável pelas reformas administrativas, expressa profunda crítica a tal imprecisão na proposta do NPR. Além das incertezas acerca de em que setores da administração seriam realizados os cortes necessários, estas eram também relativas a natureza de funcionários que seriam o alvo das reformas. Em linhas gerais, o diagnóstico dos relatórios oficiais do programa colocavam que os middle managers seriam o alvo de tais iniciativas. Tal diagnóstico, contudo, não é consensual entre os analistas dos problemas da burocracia federal, os quais expressam forte crítica às ineficiências decorrentes do excesso dos top managers e political appointees. Sobre o problema dos political appointees e das políticas de pessoal no governo americano, ver o artigo Ingraham, Patricia W., James R. Thompson and Elliot F. Einsenberg (1995)., "Political Management Strategies and Political/ Career Relationships: Where are We now in the Federal Government". Public Administration Review. May/June, v. 55. n.3. p.263-272. 
${ }^{20}$ No original "The August 1993 budget battle helped define the outcome. Senators holding the critical votes to approve the administration's first budget insisted on even bigger cuts. The administration's bargains with key members of the Congress pushed some of the NPR's money-saving ideas off the table.... The $\$ 108$ billion in deficit reduction soon become the bedrock of the movement. .. As a result, the ghost of defict reduction lurked behind every promise of empowering workers of improving performance. ... There's a major conflict between the "works better" and "costs less" objectives. ... during the first full-year of the personnel cuts, two-thirds of the reduction was to come from the Defense Department as part of the brader reduction in the defense establishment. Some other agencies were to achieve relatively small reductions. Nor was the downsizing uniform across the levels of the bureaucracy or between Washington and field offices. ... In October 1993, the administration packaged some of the reforms in H.R. 3400, the Government Reform and Savings Act. Administration officials estimated that the bill would produce $\$ 6$ billion in savings over five years. However, the Congressional Budget Office reviewed the bill and estimated that savings would be only $\$ 2.5$ billion, less than a half the amount claimed by the administration"

21 Para ver uma análise formal dos efeitos das escolhas partidárias nas políticas públicas no governo americano, considerando o efeito da alternância dos partidos como escolha estratégia dos eleitores para garantir um "maior controle sobre o governo" ver a refinada análise de Alesina, Alberto \& Howard Rosenthal (1995)., Partisan Politics, Divided Government, and the Economy. New York. Cambridge University Press.

22 No que tange aos cortes de pessoal, o NPR teve como objetivo o encolhimento das agências administrativas, não diferindo de similares experiências internacionais. No plano da implementação, entretanto, a tática utilizada foi reduzir o número de agências, reduzir o nível do gasto, e mais ainda, e especialmente, o número dos funcionários. Na realidade, tal estratégia aparece nos EUA no nível dos estados no meio dos anos 70, e depois veio a se tornar um princípio para ações no governo desde meados dos anos 80. O Presidente Reagan e a sua Grace Commission foram os primeiros a utilizar a noção de downsizing no governo federal. O Relatório inicial da comissão Grace em 1984 produzira 2.478 recomendações destinadas a reduzir os gastos das agências do governo em aproximadamente $\$ 424.4$ bilhões em três anos.

23 Esta preocupação se torna nítida no próprio título do documento produzido pela Brookings Institution em maio de 1995, Cutting Government.

24 O Office of Personnel Management (1988) regula o número de political appointees, e define várias categorias para sua utilização no Executivo federal.

25 Segundo a regulamentação específica do OPM, os funcionários SES representam o preenchimento de aproximadamente 700 cargos no nível de chefia dos departamentos e agências.

${ }^{26}$ Funcionários do tipo Schedule $C$ correspondem a aproximadamente 1.600 cargos federais preenchidos com pessoas do nível G-15 e abaixo, que atuam no nível de formulação de políticas públicas, determinando posições e fortemente envolvidos com os interesses políticos e as networks de poder no interior da burocracia. 
Alesina, Alberto, Howard Rosental. Partisan Politics, Divided Government, and the Economy. New York. Cambridge University Press, 1995.

De Witt, John, Donald F. Kettl, Barbara Dyer and W. Robert Lovan. "What will New Governance Mean for the Federal Government". Public Administration Review. March/ April, v. 54. n.2. p.170-175, 1994.

Di Iulio, John J. (ed). Deregulating the Public Service: can government be improved. Washington, D.C. Brookings Institution, 1994.

Fine Print: the Contract with America, devolution, and the administrative realities of American Federalism. Washington, D.C. Center for Public Management, Brookings Institution, 1995.

Di IUlio, John J., Gerald Garvey and Donald Kettl. Improving Government Performance. Washington D.C. Brookings Institution, 1993.

FESLER, James William and Donald F. Kettl. The Politics of the Administrative Process. New Jersey. Chatham House, 1991.

Fiorina, Morris P. Bureaucratic Failures: causes and cures. St. Louis, Mo. Center for the Study of American Business. Washington University, 1981.

Foss, Pal (ed.). Economic Approaches to Organizations and Institutions: an Introduction. Brookfield. Dartmouth, 1995.

Frederickson, George H. "Comparing the Reinventing Government Movement with the New Public Administration". Public Administration Review, v. 5, n.3. p.263-270, 1996.

Garvey, Gerald. Economic Law and Economic Growth: Antitrust, Regulation and the American growth System. New York. Greenwood Press, 1993.

. Facing the Bureaucracy: living and lying a public agency. San Francisco. Jossey-Bass, 1993.

Gore Jr, Albert. "The New Job of the Federal Executive". Public Administration Review. July/August, v. 54. n.4. p.317-321, 1994.

. Common Sense Government: works better and cost less. New York. Random, 1995.

Ingraham, Patricia W \& James R. Thompson. "The Reinvention Game". Public Administration Review. May/June, v. 55. n.3. p.291-298, 1996.

Ingraham, Patricia W., James R. Thompson and Elliot F. Einsenberg. "Political Management Strategies and Political/Career Relationships: where are we now in the Federal Government". Public Administration Review. May/June, v. 55. n.3. p.263272, 1995.

JASPER, Herbert N. and Anita F. Alpern. "National Performance Review: the good, the bad, the indifferent". Public Manager. v. 23. p.27, 1994.

Johnson, Ronald N. and Gary D. Libecap. The Federal Civil Service System and the problem of bureaucracy: the economics and politics of institutional change. Chicago.

University of Chicago Press, 1994.

KetTL, Donald and John J. DiIulio, Jr. Cutting Government. Washington, D.C. Brookings Institution, 1995.

Kettl, Donald F. Deficit Politics: public budgeting in its institutional and historical context. New York : Macmillan, 1992.

Sharing Power: public governance and private markets. Washington,

D.C. The Brookings Institution, 1993. 

State University Press, 1983.

. Reinventing Government?: appraising the National Performance Review. Washington, D.C. Brookings Institution, 1994.

KetTL, Donald F. and H. Brinton Milward. The state of public management. Baltimore. Johns Hopkins University Press, 1996.

KetTL, Donald F., John J. Di Iulio, Jr (eds). Inside the Reinvention Machine: appraising governmental reform. Washington, D.C.The Brookings Institution, 1995.

Levine, Charles H. and Rosslyn S. Kleeman. "The Quiet Crisis of the Civil of the Civil Service: the Federal Personnel System at the Crossroads". in Ingraham, Patricia W. and Donald F. Kettl (eds)., Agenda for Excellence: Public Service in America. New Jersey. Chatham House Publishers, 1992.

LowI, Theodore J. and Benjamin Ginsberg. American Government: freedom and power. New York. Norton, 1990.

MiLls, Mike. "Clinton and Gore hit the road to build a better bureaucracy". Congressional Quarterly Weekly. Sept. 11. p.2381-89, 1993.

MoE, Ronald C. "The 'Reinventing Government' Exercise: misinterpreting the problem, misjudging the consequences". Public Administration Review. March-April, p.125136, 1994.

National Performance Review (U.S). Common Sense Government : works better and costs less. Washington, D.C., 1995.

Rethinking Program Design: accompanying report of the National Performance Review. Office of the Vice President. Washington, DC, 1995.

Osborne, David and Ted Gaebler. Reinventing Government: How the entrepreneurial spirit is transforming the public sector. Massachusets. Addison-Wesley, 1992.

Rотн $J_{R}$, William. "Reinventing Government: maintaining the momentum". Public Manager, v. 22, p.15-17, 1993.

U.S GOVERNMENT. Reinventing government: hearing before the Committee on the Budget, House of Representatives, One Hundred Third Congress. Washington D.C., 1994.

The Federal Role in Privatization: hearing before the Subcommittee on Government Management, Information, and Technology of the Committee on Government Reform and Oversight, House of Representatives, One Hundred Fourthy Congress. First session, March 14, Washington : U.S. G.P.O., 1995.

United States COMmitTEe On ApPRopRiations. Downsizing government and setting priorities of federal programs: hearings before subcommittees of the Committee on Appropriations, House of Representatives, One Hundred Fourth Congress. Washington D.C., 1995.

United States Congress. Joint Economic Committee. Reinventing Government : restructuring the public sector to deliver more for less. Hearing before the Joint Economic Committee, Congress of the United States, One Hundred Second Congress. Second session, March 5, 1992. Washington : U.S. G.P.O., 1993.

United States Department of State. Change at State: "reinventing government". Washington, D.C., 1993.

WooD, B. Dan and Richard W. Waterman. Bureaucratic Dynamics: the role of bureaucracy in a democracy. Boulder : Westview Press, 1994. 
Revista do Serviço Público

Doutorando em planejamento e políticas públicas pela Cornell

University, financiada pela Capes-Brasil

\section{Abstract}

\section{Clinton e a reinvenção do governo federal: o National Performance Review Flávio da Cunha Rezende}

$\mathrm{O}$ artigo analisa o National Performance Review (NPR), programa de reforma administrativa na gestão do presidente Clinton, implementado em 1993, e que traduz o novo paradigma empreendedorialista proposto para o funcionamento da burocracia do governo federal americano.

Na primeira parte são apresentados os princípios, objetivos e natureza da agenda, ressaltando-se as suas bases conceituais. Segue-se uma análise sobre a formação da agenda e a seqüência da sua implementação. A 3 a parte compreende uma visão da dinâmica político-institucional, com destaque para as tensões observadas entre o Legislativo e o Executivo, e o impacto destas nas mudanças da agenda. Na última seção, apresenta-se um painel empírico sobre alguns dos resultados em determinadas agências e departamentos do Governo, pretendendo-se oferecer contribuições ao processo de reformas administrativas atualmente em curso no Brasil.

\section{Clinton y la reinvención del gobierno federal: el National Performance Review Flávio da Cunha Rezende}

El artículo analisa el National Performance Review (NPR), programa de reforma administrativa en la gestión del presidente Clinton, implementado en 1993, y que traduce el nuevo paradigma emprendedor propuesto para el funcionamiento de la burocracia del gobierno federal estadounidense.

En la primera parte se presentan los principios, objetivos y naturaleza de la agenda, distinguiéndose sus bases conceptuales. En seguida, se hace un análisis sobre la formación de la agenda y la secuencia de su implementación. La tercera parte comprende una visión de la dinámica político-institucional, destacándose las tensiones observadas entre el Legislativo y el Ejecutivo, y el impacto de éstas en los cambios de la agenda. En la última sección, se presenta un panel empírico sobre algunos de los resultados en determinadas agencias y departamentos del gobierno, buscándose ofrecer contribuciones al proceso de reformas administrativas actualmente en curso en Brasil.

\section{Clinton and the reinvention of federal government: the National Performance Review \\ Flávio da Cunha Rezende}

The paper analyses the National Performance Review (NPR), the programme for administrative reform in president Clinton's administration, implemented in 1993, which translates the new entrepreneurial paradigm proposed for the functioning of the American federal government's bureaucracy.

In the first part, the principles, objectives and the nature of the agenda are presented, with special emphasis on its conceptual bases. It is followed by an analysis of the agenda background and the sequence of its implementation. The third part covers a vision of the political and institutional dynamics, highlighting the tensions observed between the Legislative and the Executive Branches, and the impact of these on the changes in the agenda. In the last section, an empirical panel about some of the outcomes in certain Government agencies and departments is shown, intending to offer contributions to the administrative reform process currently under way in Brazil. 